Review

\title{
A State-of-the-Art Review on Core-Shell Pigments Nanostructure Preparation and Test Methods
}

\author{
Kwok Wei Shah 1 , Ghasan Fahim Huseien * and Harn Wei Kua * \\ Department of Building, School of Design and Environment, National University of Singapore, Singapore 117566, \\ Singapore; bdgskw@nus.edu.sg \\ * Correspondence: bdggfh@nus.edu.sg (G.F.H.); bdghkuahw@nus.edu.sg (H.W.K.); Tel.: +65-565163425 (G.F.H.); \\ $+65-565163425$ (H.W.K.)
}

Citation: Shah, K.W.; Huseien, G.F.; Kua, H.W. A State-of-the-Art Review on Core-Shell Pigments Nanostructure Preparation and Test Methods. Micro 2021, 1, 55-85. https://doi.org/ $10.3390 /$ micro1010006

Academic Editor: Gonzalo Abellán

Received: 15 June 2021

Accepted: 5 July 2021

Published: 9 July 2021

Publisher's Note: MDPI stays neutral with regard to jurisdictional claims in published maps and institutional affiliations.

Copyright: (c) 2021 by the authors. Licensee MDPI, Basel, Switzerland. This article is an open access article distributed under the terms and conditions of the Creative Commons Attribution (CC BY) license (https:// creativecommons.org/licenses/by/ $4.0 /)$.
Abstract: Uses of novel technologies for improving the durability and lifespan of the construction materials have emerged as viable solutions toward the sustainable future wherein the coating industry plays a significant role in economy growth and better livelihoods. Thus, the continual innovation of various technologies to introduce diverse market products has become indispensable. Properties of materials like color stability under UV, elevated temperatures and aggressive environments, and skid and abrasion resistance are the main challenges faced by commercial coating materials, leading to more demand of natural materials as sustainable agents. Lately, nanostructured core-shell pigments with unique compositions have widely been utilized in composite materials to enhance their properties. Core-shell particles exhibit smart properties and have immense benefits when combined with building materials. Based on these facts, we comprehensively overviewed the state-ofthe-art research of core-shell nanomaterials in terms of their preparation and performance evaluation methods, as well as feasible applications. The first part of this article discusses effective shell materials, including most common silica and titanium oxides. In addition, nanotechnology enabling the production and patterning of low-dimensional materials for widespread applications is emphasized. The second part deals with various potential core materials used to achieve core-shell nanostructures. The third part of this paper highlights some interesting mechanisms of core-shell structures in the modified systems that display high stability, durability, efficiency, and eco-friendliness. Finally, different applications of these core-shell nanostructures are underscored together with their test methods to evaluate their performances.

Keywords: nanotechnology; core-shell pigments; $\mathrm{SiO}_{2} ; \mathrm{TiO}_{2} ; \mathrm{Fe}_{2} \mathrm{O}_{3} ;$ cyclist roads

\section{Introduction}

In recent years, synthetically colored pigments have been introduced in various market products. Consequently, they have been the subject of extensive scientific investigation. The most common uses of pigments are in paints, varnishes, printing inks, plastics and textiles, leather decoration, building materials, rubber, paper, ceramic glazes, and so forth [1,2]. The durability of pigments refers to their capacity to withstand weathering processes and avoid deterioration when exposed to an external environment [3]. Studies have revealed that efficient uses of energy for construction materials production can protect the environment [4]. Thus, the development of durable and sustainable pigments has become fundamental in the construction industry. Diverse methods have been introduced to improve the durability of pigments, especially the core-shell approach for smart/functional materials preparation [5-8].

Earlier, different chemical techniques have been developed to prepare high-quality core-shell nanostructures. The multicomponent materials were shown to have better properties due to their diverse compositions and structures, making them versatile for widespread applications [9-12]. Owing to their distinct properties, core-shell structures 
have received intense research attention. These structures are more advantageous than other composite materials. For example, they can strengthen or generate new chemical and physical capabilities, facilitate the structural integrity desirable for self-maintenance, stop the core from breaking up into large particles, and ensure effective dispersion. In addition, they offer other benefits, like typical multifunctional compositions and structures. A higher performance can be achieved in the presence of synergy between the shells and cores [13].

The properties of materials obtained from core-shell particles can be finely tuned, making them fundamentally interesting in the fields of science and technology $[1,14,15]$. In every core/shell particle, there is a core structural domain cloaked by a shell domain. Various types of materials can constitute the core and shell domains, such as metals, polymers, and inorganic solids. It is easy to modify the structure, size, and composition of these particles to customize their mechanical, optical, magnetic, thermal, catalytic, electrical, and electro-optical attributes. To create hollow spheres and reduce the expenditure of these precious materials, core/shell morphology can be employed, in which the materials with relatively cheaper cores are coated with expensive materials $[16,17]$.

Nanoparticles are defined as particles with diameters below $0.1 \mu \mathrm{m}$, and such particles are attractive for diverse functional applications. In essence, these nanoparticles can be considered as smart materials due to their distinctive properties. Nanoscale systems are more advantageous than microscale, macroscale, and bulk materials because of their large surface area-to-volume ratios and quantum size effects $[18,19]$. The development of new and advanced synthesis methods has enabled the production of symmetrical (spherical) and various other shaped nanoparticles (e.g., cube, prism, hexagon, wire, rod, and tube) [20-22]. Nonetheless, the preparation and characterization of differently shaped nanoparticles have only been performed recently. Some reports have indicated that it is relatively easier to make non-spherical nanoparticles than other shapes [23-25]. It is important to note that the properties of these nanoparticles are both size- and shapedependent. For instance, some properties of magnetic nanocrystals (including blocking temperatures, permanent magnetization, and magnetic saturation) are determined by their particle size, whereas the coercivity of such a system is decided by their shape due to its impact on the surface anisotropy. For this reason, nanoparticles are often used to improve the pigment performance [26].

Nanotechnology has developed rapidly in recent years, and consequently, core-shell nanoparticles (NPs) have emerged as the key functional material. Currently, many researchers have been investigating core-shell NPs with different functional compositions. They find a wide range of applicability in various fields, including biomedicine, electronics, optics, catalysis, and pharmaceuticals [27]. Core-shell nanoparticles have distinct physiochemical traits and, thus, attract substantial research interests [22,28]. The key advantages of core-shell nanoparticles are enhanced levels of protection, encapsulation, and controlled release. Different types of core/shell nanoparticles have been identified and applied for various practical purposes. However, it remains challenging to classify all the available core/shell nanoparticles based on their industrial applications due to their wide varieties. Some studies were conducted on the pigments made from core-shell nanoparticles to outline their production methods and the nature of their core and shell materials, as well as their uses. Considering the immense benefits of core-shell nanostructures, this paper will analyze the key features and properties of such nanosystems. The features of inorganic materials and their fabrication methods and common uses are underscored. First, a brief overview of the different methods for the production of these particles is underlined. Next, different classes of existing core-shell materials and their uses are highlighted. Later, various latest techniques for the synthesis of core-shell pigment nanocapsules, followed by the use of core-shell nanoparticles in road paints, are explored. Finally, the paper is concluded, followed by some recommendations for further research and development within this field. Figure 1 provides the overall structure of this paper. 


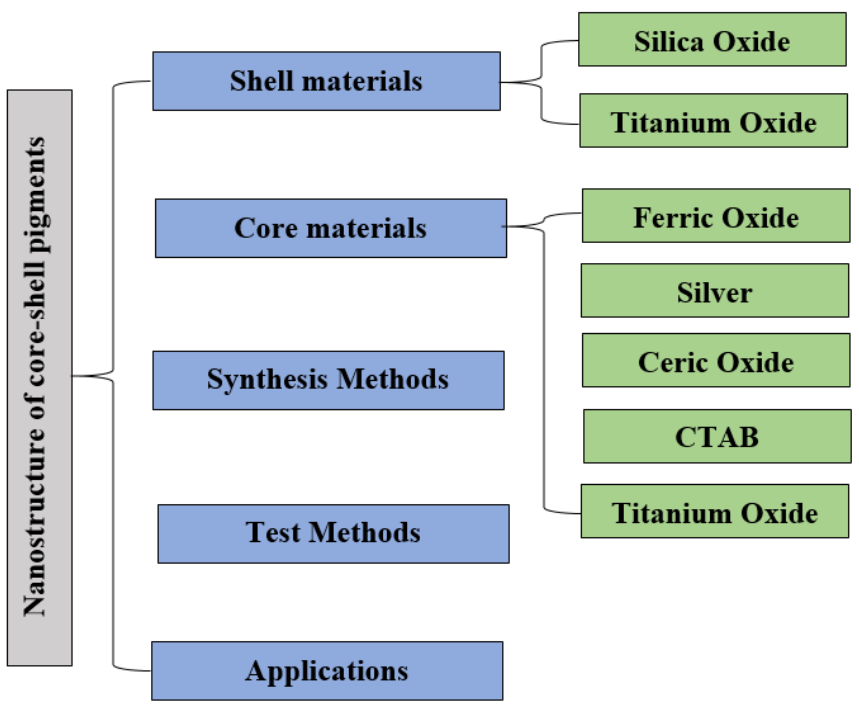

Figure 1. Flow chart of core-shell pigment materials, synthesis, test methods, and applications. CTAB: Cetrimonium bromide $\left(\left[\left(\mathrm{C}_{16} \mathrm{H}_{33}\right) \mathrm{N}\left(\mathrm{CH}_{3}\right)_{3}\right] \mathrm{Br}\right)$.

\section{Core-Shell Nanoparticle: Synthesis Approach and Importance}

Nanotechnology refers to the atomic-level manipulation of materials that can be performed by combining the engineering, chemical, and biological approaches. Several techniques can be used to synthesize nanoparticles, like chemical, biological, physical, and even hybrid approaches (Figure 2). Generally, two key types of approaches are used for the production of nanostructures: "top-down" and "bottom-up". In the former ("top-down") approach, traditional workshops and microfabrication techniques are used in addition to externally controlled equipment to cut, mill, shape, and mold materials into their desired forms. The most common top-down methods are the lithographic techniques (e.g., UV, electron or ion beam, optical near-field scanning, laser beam processing, and scan probing) and mechanical methods (i.e., machining, grinding, and polishing) [29-32]. Conversely, the "bottom-up" approaches focus on the manipulation of the chemical properties of molecules, forcing them to self-assemble into a new and more beneficial form with emergent traits. The most commonly employed bottom-up approaches include chemical synthesis, laserinduced assembly, chemical vapor deposition, colloidal aggregation, self-assembly, and film deposition and growth $[33,34]$. Both approaches have strengths and weaknesses. Nonetheless, one key advantage of the bottom-up approach is that it can create much smaller particles and may be more cost-effective than the top-down approach due to its absolute precision, minimal energy loss, and complete control over the whole process. With regards to the synthesis of core/shell nanoparticles, ultimate control is needed to create a uniform coating around the core materials while the particles are forming. In this respect, a bottom-up approach would be more appropriate. In addition, a hybrid approach can also be used. For example, a top-down approach may be used to make the core, and a bottom-up approach can be subsequently employed to maintain the shell's thickness. As water droplets can serve as nanoreactors, the use of microemulsion is also recommended to regulate the size and thickness of shells.

Nowadays, several researchers are turning their attention towards core/shell nanostructures because of their great benefits in a raft of fields, including chemistry, electronics, pharmaceuticals, optics, biomedicine, and catalysis. Additionally, these nanoparticles are highly functional and show specialized properties, wherein the characteristics of the core or shell materials can be entirely different. It is possible to modify these properties by altering the materials or the core-to-shell ratio [35]. Interestingly, the reactivity and thermal stability of the core materials can be changed by modifying the shell coating, thereby enhancing the stability and dispersion of the core particles. This, in turn, results in unique properties of each material employed, wherein the resultant product has an inherent ability to modify 
the surface functions based on the environment when implemented [36]. Some benefits of coating the core particles include the facilitation of surface modifications; enhanced functionality, stability, and dispersion of core particles; the significant reduction of expensive material consumption; and controlled release of the core.

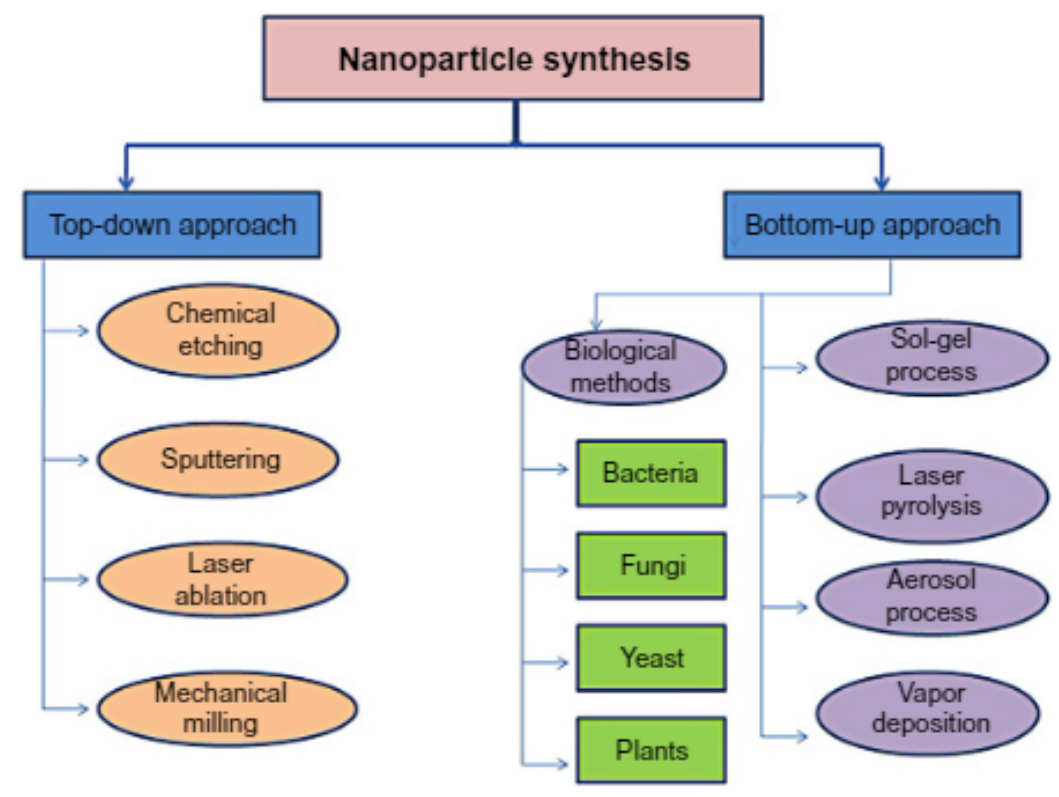

Figure 2. The synthesis of nanoparticles using different approaches [37].

\section{Materials Based Shell Component}

Core-shell nanoparticles are made up of multiple materials, including metals and biomolecules, with one forming the central core and the other covering the core in the form of a shell. Core-shell nanostructures have excellent thermal and chemical stabilities, high levels of solubility, low toxicity, and greater permeability toward certain target cells, making them immensely useful for a variety of uses. Micro-nanoscale core/shell particles have distinct compositions that make then unique compared to other types of particles. They effectively bring together the properties of the materials used in the core and shell, as well as the smart properties generated through the individual component materials. Of late, increasing research attention has been paid to the production and use of coreshell structures [38], especially in the pigment industry. To be more specific, core-shell materials have widely been applied to improve the durability of pigments (Table 1). To meet the ongoing demand, diverse organic and inorganic materials have been produced to achieve the optimum core-shell nanostructure. For example, Cao et al. [39] examined inorganic-organic hybrid pigments using an inorganic mixture of precipitated $\mathrm{SiO}_{2}$ and $\mathrm{TiO}_{2}$. Mesoporous soft template synthesis has been used to fabricate a dye core@silica shell structure [40]. At this point, it is customary to describe some beneficial inorganic materials used to produce the shells in core-shell structures, particularly $\mathrm{SiO}_{2}$ and $\mathrm{TiO}_{2}$.

\section{1. $\mathrm{SiO}_{2}$-Based Shells}

The encapsulation of individual pigment nanoparticles using a compact and durable shell is the most common approach. Several researchers have also put forward a reverse silica pigment topology [41-46]. Silicon is a very good material to use for core-shell coatings, because it is transparent, inert, and available in abundance. For this reason, it has been selected for use in many pigment encapsulation processes, such as in situ sol-gel reactions (with silica products used as precursors, including potassium/sodium silicate solutions) [47,48], various silanes with fumed silica [49], or tetraethoxysilane (TEOS), which is perhaps the most commonly used silica precursor [50]. A ball-milling treatment using silica nanoparticles can also be used for this purpose [51]. A layer-by-layer method of 
pre-synthesizing silica nanoparticles is also popular [52]. Silica is an excellent inorganic material to use for coating core-shell particles and useful in diverse fields, including biotechnology, medicine, and biomedical sensing. Distinct properties of silica, such as its high chemical stability, low cost, and great formability, enable the production of microscale particles from larger spherical particles.

Lu et al. [53] used the sol-gel method to hydrolyze tetraethyl orthosilicate (TEOS) to cover the iron oxide nanoparticles in uniform shells. By changing the sol-gel precursor concentration, the thickness of these silica shells was modified. Fluorescent dyes were added to these silica shells via the process of covalent coupling, in which the organic dyes and sol-gel precursor joined together. Silica $\left(\mathrm{SiO}_{2}\right)$-coated ceria $\left(\mathrm{CeO}_{2}\right)$ nanoparticles were grown [54] via the water-in-oil microemulsion process. The $\mathrm{SiO}_{2}$-covered $\mathrm{CeO}_{2}$ nanoparticles were synthesized using cyclohexane (99\%) as the organic phase, wherein reverse micelles on polyoxyethylene (15) cetylether were formed. The surfactant used in the organic solution had a concentration of $0.5 \mathrm{~mol} / \mathrm{L}$. Additionally, $\mathrm{CeO}_{2}$ was sourced from cerium nitrate and cerium chloride (cerium nitrate hexahydrate, $\mathrm{Ce}\left(\mathrm{NO}_{3}\right)_{3} \cdot 6 \mathrm{H}_{2} \mathrm{O}$, purity $99 \%$ and cerium chloride, $\mathrm{CeCl}_{3}$, purity $\left.99.9 \%\right)$. Subsequently, a liquid phase $(4.0 \mathrm{~mL}$, represented as aq.) of cerium ions $\left(\mathrm{Ce}\left(\mathrm{NO}_{3}\right)_{3}\right.$ aq. and $\mathrm{CeCl}_{3}$ aq.) was added to the organic surfactant solution with the concentration of $0.14 \mathrm{~mol} / \mathrm{L}(100 \mathrm{~mL})$. The resultant mixture was magnetically stirred at $50{ }^{\circ} \mathrm{C}$, allowing the formation of a microemulsion solution. Either an ammonium solution $\left(\mathrm{NH}_{4} \mathrm{OH}\right.$ aq., $2.70 \mathrm{~mol} / \mathrm{L}, 3.0 \mathrm{~mL}$ ) or oxalic acid solution $\left((\mathrm{COOH})_{2}\right.$ aq., $\left.1 \mathrm{~mol} / \mathrm{L}, 3.0 \mathrm{~mL}\right)$ was used as the $\mathrm{CeO}_{2}$ precursor agent. $\mathrm{The}^{\mathrm{SiO}_{2}}$ was obtained from tetraethylorthosilicate (TEOS; $0.86 \mathrm{~mol} / 1$ of microemulsion solution) and used to produce a $\mathrm{NH}_{4} \mathrm{OH}$ solution $(2.70 \mathrm{~mol} / \mathrm{L}, 15.0 \mathrm{~mL})$. Then, it was added to the microemulsion with the $\mathrm{CeO}_{2}$ precursor nanoparticles, followed by hydrolysis of the solution for one hour at $50{ }^{\circ} \mathrm{C}$. Throughout the TEOS hydrolysis process, the water-tosurfactant molar ratio was maintained at 23 . It was impossible to accurately measure the $\mathrm{pH}$ of the microemulsion. An electric $\mathrm{pH}$ gauge was used to make an approximation with the meter reading ranging from 11.0 to 11.5. The solution was centrifuged after removing the $\mathrm{CeO}_{2}$ precursor nanoparticles from $\mathrm{SiO}_{2}$, followed by bath in propanol, and then left at $80{ }^{\circ} \mathrm{C}$ to dry overnight. Finally, it was calcined for $5 \mathrm{~h}$ at $400^{\circ} \mathrm{C}$ to eliminate the surfactant.

The chemical liquid deposition technique was used to produce aluminum pigments covered in $\mathrm{SiO}$ from the tetraethyl silicate precursor (TEOS) [55]. The $\mathrm{SiO}_{2}$-coated aluminum particles were grown using $10 \mathrm{~g}$ of aluminum flakes inserted into $100 \mathrm{~mL}$ of pure ethanol followed by ultrasonic treatment for half an hour. A well-dispersed aluminum suspension was obtained, and then, TEOS was added. Subsequently, the aluminum suspension was put into a three-neck flask of $1000-\mathrm{mL}$ capacity and then placed in a water bath before being stirred at a rate of $500 \mathrm{rpm}$ at $40{ }^{\circ} \mathrm{C}$. After, a solution consisting of $28 \%$ ammonia was supplemented together with a certain quantity of distilled water, plus $16 \mathrm{~mL}$ of pure ethanol. Next, TEOS was diluted using $12 \mathrm{~mL}$ of pure ethanol. The used mole ratios of TEOS-to-Al throughout the experiment were 1:44, 1:22, and 1:11. Moreover, the mole ratio of distilled water-to-TEOS was kept constant at 30:1. The solutions discussed above were then placed into an aluminum suspension via two continuous flow pumps at a constant flow rate, with a feeding time of $1 \mathrm{~h}$. The newly produced suspension was then stirred for $5 \mathrm{~h}$ at $40^{\circ} \mathrm{C}$. The precipitate was filtrated and then was washed multiple times with pure ethanol. It was then placed in an electric oven at $120^{\circ} \mathrm{C}$ for $12 \mathrm{~h}$ and at $200{ }^{\circ} \mathrm{C}$ for another $2 \mathrm{~h}$ for drying.

Ahmed et al. [56] used zinc, calcium, and strontium nitrate solutions to produce ferrite/silica core-shell pigments, wherein ferric nitrate were mixed with silica fume. After the solution was stirred for $60 \mathrm{~min}$ at $100{ }^{\circ} \mathrm{C}$, the resultant paste was heated in an oven at $400{ }^{\circ} \mathrm{C}$. Finally, the paste was ground and calcined at $750^{\circ} \mathrm{C}$. The Stöber method was used [57] to grow crystals of $\mathrm{SiO}_{2}$-covered $\mathrm{Sr}^{2+}$-doped red $\gamma-\mathrm{Ce}_{2} \mathrm{~S}_{3}\left(\mathrm{Sr}^{2+}\right.$-doped $\gamma$ $\left.\mathrm{Ce}_{2} \mathrm{~S}_{3} @ \mathrm{c}-\mathrm{SiO}_{2}\right)$ pigments. In this process, amorphous $\mathrm{SiO}_{2}\left(\mathrm{a}-\mathrm{SiO}_{2}\right)$ sol and $\mathrm{Sr}^{2+}$-doped $\mathrm{CeO}_{2}$ were used as precursors. The original materials used in this experiment were $\mathrm{Si}\left(\mathrm{OC}_{2} \mathrm{H}_{5}\right)_{4}$ (TEOS), $\mathrm{Sr}\left(\mathrm{NO}_{3}\right)_{2}, \mathrm{Ce}\left(\mathrm{NO}_{3}\right)_{3} \cdot 6 \mathrm{H}_{2} \mathrm{O},\left(\mathrm{NH}_{4}\right)_{2} \mathrm{CO}_{3}$, ammonia water, and ethanol. 
The following process was conducted to acquire the $\mathrm{Sr}^{2+}$-doped $\mathrm{CeO}_{2}$ pigment precursor. First, the placement of $\mathrm{Sr}\left(\mathrm{NO}_{3}\right)_{2}$ and $\mathrm{Ce}\left(\mathrm{NO}_{3}\right)_{3} \cdot 6 \mathrm{H}_{2} \mathrm{O}$ with a Sr${ }^{2+} / \mathrm{Ce}^{3+}$ mole ratio of 0.15 was incorporated into deionized water to dissolve the particles, producing a homogeneous solution. Second, the precipitant $\left(\mathrm{NH}_{4}\right)_{2} \mathrm{CO}_{3}$ was added to the solution to produce some white precipitate. Next, the precipitate was filtered and washed several times using water before being left at $80{ }^{\circ} \mathrm{C}$ for $12 \mathrm{~h}$ to dry. Afterward, it was calcined for $1 \mathrm{~h}$ in a muffle furnace at $1000{ }^{\circ} \mathrm{C}$. Finally, it was left to cool down naturally, producing $\mathrm{Sr}^{2+}$-doped $\mathrm{CeO}_{2}$. Later, TEOS was dissolved in a solution containing water and alcohol, whilst ammonia water $(25.0 \mathrm{wt} \%)$ was used to change the solution's $\mathrm{pH}$ level to 11.00 . The solution was then stirred for $0.5 \mathrm{~h}$ and kept in an $80{ }^{\circ} \mathrm{C}$ water bath for six hours to produce $\mathrm{SiO}_{2}$ sol. The resultant $\mathrm{Sr}^{2+}$-doped $\mathrm{CeO}_{2}$ was added to the $\mathrm{SiO}_{2}$ sol at a $\mathrm{Ce}^{3+} / \mathrm{Si}^{4+}$ mole ratio of $0.2,0.4,0.6,0.8$, or 1 and stirred for $0.5 \mathrm{~h}$ before being left to dry at $80^{\circ} \mathrm{C}$. This produced the precursor $\mathrm{Sr}^{2+}$-doped $\gamma-\mathrm{Ce}_{2} \mathrm{~S}_{3} @_{\mathrm{c}}-\mathrm{SiO}_{2}$ red pigments in powder form. Afterward, this powder was treated in a tubular furnace with a gas flow containing both argon and $\mathrm{CS}_{2}$ $(100 \mathrm{~mL} / \mathrm{min})$. The vulcanization temperatures of the furnace were changed intermittently $\left(880\right.$ to $920^{\circ} \mathrm{C}$ ) over a period of two hours. Once sulfurization occurred, the powder was subjected to calcination in argon gas at various temperatures $\left(1100\right.$ to $\left.1250^{\circ} \mathrm{C}\right)$ for $60 \mathrm{~min}$ and left to cool down naturally to room temperature. The process yielded $\mathrm{Sr}^{2+}$-doped $\gamma-\mathrm{Ce}_{2} \mathrm{~S}_{3} @_{\mathrm{c}-\mathrm{SiO}_{2}}$ red pigments, which were later treated with 2-M HCl for $6 \mathrm{~h}$. Finally, the colors of the samples were compared before and after acid etching.

Mjejri et al. [58] fabricated core-shell $\mathrm{Zn}_{1-x} \mathrm{Co}_{\mathrm{x}} \mathrm{O} @ \mathrm{SiO}_{2}$ nanoparticles with green pigments using $\mathrm{SiO}_{2}$-based shell materials. The main objective was to create particles with high chemical stability and low cytotoxicity. A polyol process was used to form $\mathrm{ZnO}$ doped with $\mathrm{Co}^{2+}$, a well-known substitute for chromium-based inorganic pigments. Additionally, to source the zinc and cobalt needed in the experiment, zinc acetate dihydrate $\left(\mathrm{Zn}\left(\mathrm{CH}_{3} \mathrm{OO}\right)_{2} \cdot 2 \mathrm{H}_{2} \mathrm{O}\right)$ and cobalt nitrate $\left(\mathrm{Co}\left(\mathrm{NO}_{3}\right)_{2} \cdot 6 \mathrm{H}_{2} \mathrm{O}\right)$ were utilized, wherein diethylene glycol $\left(\mathrm{H}_{10} \mathrm{C}_{4} \mathrm{O}_{3}\right)$ was used as the template. Upon adding zinc and cobalt precursors into the solution at a stoichiometric proportion, $1 \mathrm{~g}$ of $\mathrm{Zn}_{1-x} \mathrm{Co}_{x} \mathrm{O}$ powder $(2.924 \mathrm{~g})$ was obtained. Subsequently, the powder was supplemented with $250 \mathrm{~mL}$ of $\mathrm{H}_{10} \mathrm{C}_{4} \mathrm{O}_{3}$. The resultant mixture was then continually stirred for $1 \mathrm{~h}$ before being heated at $180{ }^{\circ} \mathrm{C}$ to produce a green sol. Next, the precipitate was centrifuged and then washed multiple times in pure ethanol to eliminate the residual organic product. Then, it was oven-dried at $80^{\circ} \mathrm{C}$. Later, tetraethoxysilane (TEOS and $\left.\mathrm{Si}\left(\mathrm{OC}_{2} \mathrm{H}_{5}\right)_{4}\right)$ was subjected to hydrolysis, followed by condensation in an alcohol solution $(\mathrm{EtOH})$. The Stöber experiment was conducted to produce $\mathrm{Zn}_{1-\mathrm{x}} \mathrm{Co}_{\mathrm{x}} \mathrm{O} @ \mathrm{SiO}_{2}$ core shells. In this process, about $100 \mathrm{mg}$ of powder was added to $150 \mathrm{~mL}$ of EtOH and $6.4 \mathrm{~mL}$ of $\mathrm{NH}_{4} \mathrm{OH}$ as a hydrolysis-condensation catalyst. To vary the thicknesses of the $\mathrm{SiO}_{2}$ shells, various quantities of TEOS were added slowly to the solution as a prepared suspension. Subsequently, the suspension was kept at room temperature for two hours under constant agitation. Once the solution got matured, a few drops of HCL liquid solution $(0.2 \mathrm{M})$ were added to ensure the complete dissolution of the $\mathrm{ZnO}$ cores, producing some porous silica shells.

The hydrothermal Stöber techniques were used effectively to produce $\alpha-\mathrm{Fe}_{2} \mathrm{O}_{3} @ \mathrm{SiO}_{2}$ reddish pigments with core-shell structures [28]. The reddish pigments of $\alpha-\mathrm{Fe}_{2} \mathrm{O}_{3}$ acted as chromophores and tetraethoxysilane (TEOS, AR) as the source of the silica. First, $0.05 \mathrm{~g}$ of $\alpha-\mathrm{Fe}_{2} \mathrm{O}_{3}$ and polyvinyl pyrrolidone (PVP-30) were dissolved in $100 \mathrm{~mL}$ of deionized water and then subjected to ultrasonication for $15 \mathrm{~min}$. This produced a homogeneous solution, which was stirred at room temperature continually for $12 \mathrm{~h}$. The resultant solution was centrifuged multiple times to collect the PVP-modified $\alpha-\mathrm{Fe}_{2} \mathrm{O}_{3}$ following three times bathing in ethanol and deionized water. Later, the as-obtained $\alpha-\mathrm{Fe}_{2} \mathrm{O}_{3}$ was mixed in $100 \mathrm{~mL}$ of ethanol and subjected to an ultrasound for $5 \mathrm{~min}$ until the solution became homogeneous. Afterward, various contents of ammonia (0.5, 1.5, and $2.5 \mathrm{~mL})$ and tetraethoxysilane $(0.1,0.3$, and $0.5 \mathrm{~mL})$ were supplemented into the solution with continuous stirring. Table 1 explains the experimental conditions of each sample. The resultant solution was stirred for $6 \mathrm{~h}$ at room temperature, forming $\alpha-\mathrm{Fe}_{2} \mathrm{O}_{3} @ \mathrm{SiO}_{2} \mathrm{NPs}$. 
The as-prepared $\alpha-\mathrm{Fe}_{2} \mathrm{O}_{3} @ \mathrm{SiO}_{2} \mathrm{NPs}$ were left for $12 \mathrm{~h}$ at $70{ }^{\circ} \mathrm{C}$ to dry before being calcined at $1000{ }^{\circ} \mathrm{C}$ for $1 \mathrm{~h}$. Figure 3 illustrates the process of fabricating $\alpha-\mathrm{Fe}_{2} \mathrm{O}_{3} @ \mathrm{SiO}_{2}$ pigments with core-shell structures.

Fabjan et al. [48,59] produced multilayered $\mathrm{SiO}_{2}$ core-shell pigments by adding ethoxylated alcohol (EA) and hexadecyl-trimethylammonium bromide (CTAB) to distilled water to fabricate a surfactant solution. The red pigment was then incorporated into the solution to create a pigment dispersion of $1 \mathrm{wt} \%$. Meanwhile, a mild basic solution was used by $\mathrm{Yu}$ et al. [60] to coat the $\mathrm{SiO}_{2}$ shells in order to produce $\alpha-\mathrm{Fe}_{2} \mathrm{O}_{3} @ \mathrm{SiO}_{2}$ nanoparticles. First, $\alpha-\mathrm{Fe}_{2} \mathrm{O}_{3}$ nanoparticles in spindle shapes were fabricated that served as the core materials. Next, these nanoparticles were covered by silica through the sol-gel technique. The original materials used (obtained from Aldrich) in the process were $\mathrm{FeCl}_{3} \cdot 6 \mathrm{H}_{2} \mathrm{O}(97 \%)$, tetraethylorthosilicate (TEOS of $99.99 \%$ purity), cetyltrimethylammonium bromide (CTAB, 99\%), and $\mathrm{NH}_{4} \mathrm{OH}$ ( $28 \%$ in water of $99.99 \%$ purity). Additionally, deionized water was employed, and the Stöber method was applied to treat the hematite with silica. Then, the silica shells were selectively etched using the $\mathrm{NH}_{4} \mathrm{OH}$ solution. The resultant silica-coated hematite powder was then placed in distilled water $(10 \mathrm{~mL})$, whilst $1 \mathrm{~mL}$ and $10 \mathrm{~mL}$ of $\mathrm{NH}_{4} \mathrm{OH}$ solution were poured into the hematite solutions to change the etchants' concentrations. The resultant mixtures were centrifuged, and the solutions were kept at $80^{\circ} \mathrm{C}$ in vacuum to dry. The samples were then subjected to heat treatments at either room temperature or higher temperatures $\left(300\right.$ and $1000{ }^{\circ} \mathrm{C}$ ) for sixty minutes before the physical properties of each sample were compared. This enabled the researcher to assess the coloration and heat stability of each etched sample.

Wang et al. [61] conducted a study to grow $\mathrm{ZnS} @ \mathrm{SiO}_{2}$ core-shell nanoparticles using a homogeneous deposition method, in which deionized water $(1 \mathrm{~mL})$ and ammonia $(0.5 \mathrm{~mL})$ were mixed with $30 \mathrm{~mL}$ of $\mathrm{ZnS}(0.5-2 \mathrm{wt} \%)$ colloidal solution, and the obtained solution was stirred for $60 \mathrm{~min}$. Subsequently, TEOS $(0.5-2 \mathrm{~g})$ was incorporated in the silica-coated material, and the reactions occurred at room temperature over a period of $5 \mathrm{~h}$. After the reactions were completed, the resultant core-shell particles were collected and subjected to centrifugation in order to purify them. Subsequently, the particles were redispersed in water and ethanol multiple times. Lui et al. [62] treated $\gamma-\mathrm{Ce}_{2} \mathrm{~S}_{3}$ red pigments with a silica layer using the Stöber technique combined with a hydrogen-argon atmosphere heat treatment $\left(700^{\circ} \mathrm{C}\right)$. Figure 3 shows the experimental procedure for the silica-coated $\gamma-\mathrm{Ce}_{2} \mathrm{~S}_{3}$ pigments' fabrication. In this process, first, untreated $\gamma-\mathrm{Ce}_{2} \mathrm{~S}_{3} @ \mathrm{SiO}_{2}$ pigments $(2.0 \mathrm{~g})$ and CTAB $(0.2 \mathrm{~g})$ particles were stirred into a solution containing $200 \mathrm{~mL}$ of ethanol and $250 \mathrm{~mL}$ of deionized water for a period of $24 \mathrm{~h}$. Next, the solution was centrifuged to separate the particles, allowing the collection of pretreated, uncoated $\gamma-\mathrm{Ce}_{2} \mathrm{~S}_{3} @ \mathrm{SiO}_{2}$ pigments. Second, a solution containing water and ethanol was made with an established volume ratio, and then, ammonia water was added to change the $\mathrm{pH}$ value to approximately 10.5. The pretreated uncoated $\gamma-\mathrm{Ce}_{2} \mathrm{~S}_{3} @ \mathrm{SiO}_{2}$ pigments were then placed into the solution. Later, TEOS was added to the solution using a continuous flow pump, producing a sol mixture that was stirred for $3 \mathrm{~h}$ at $40^{\circ} \mathrm{C}$. Afterward, the sol mixture was centrifuged, washed in ethanol several times, and left in an oven at $70{ }^{\circ} \mathrm{C}$ to dry, yielding a $\mathrm{SiO}_{2}$ xerogel-coated $\gamma-\mathrm{Ce}_{2} \mathrm{~S}_{3}$. Finally, the $\mathrm{SiO}_{2}$ xerogel-coated $\gamma-\mathrm{Ce}_{2} \mathrm{~S}_{3}$ particles were inserted into a sealed double crucible and annealed in a hydrogen-argon gas mixture at $700{ }^{\circ} \mathrm{C}$ for $2 \mathrm{~h}$ in order to fabricate $\gamma-\mathrm{Ce}_{2} \mathrm{~S}_{3} @ \mathrm{SiO}_{2}$ pigments. 


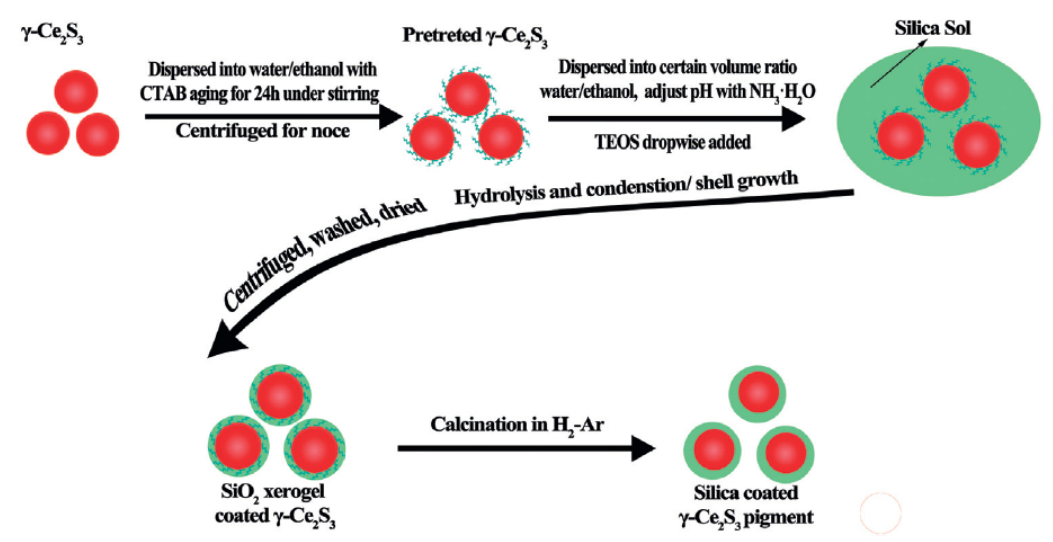

Figure 3. Experimental process schematic of the preparation of $\gamma-\mathrm{Ce}_{2} \mathrm{~S}_{3} @ \mathrm{SiO}_{2}$ [62].

Colloidal silica nanoparticles were used in a sol-gel process to coat the natural pigment of hematite (red ocher, $\alpha-\mathrm{Fe}_{2} \mathrm{O}_{3}$ ) [63], wherein the main objective was to produce a longlasting hematite pigment of the $\mathrm{Fe}_{2} \mathrm{O}_{3} @ \mathrm{SiO}_{2}$ nanocomposite that may be used to preserve artefacts. To achieve this, $2.2 \mathrm{wt} \%$ of pure $\alpha-\mathrm{Fe}_{2} \mathrm{O}_{3}$ in the silica sol was charged over a prolonged time and continually stirred. The process of coating the $\mathrm{Fe}_{2} \mathrm{O}_{3}$ particles with SiNP lasted for $60 \mathrm{~min}$. Finally, a Buchner funnel was used to gather the resultant $\mathrm{Fe}_{2} \mathrm{O}_{3} @ \mathrm{SiO}_{2}$, which was initially washed using absolute ethanol and, then, by deionized water before being left to dry at $135^{\circ} \mathrm{C}$.

All-inclusive analyses of the previous literature revealed that $\mathrm{SiO}_{2}$ as the shell of a metal oxide core decreases the bulk conductivity and increases the suspension stability of the prepared core-shell particles. Moreover, the optical transparency of $\mathrm{SiO}_{2}$ allows a spectroscopic investigation of the core. The $\mathrm{SiO}_{2}$ shell is also helpful in increasing the thermal stability of the core materials. The toxic nature and ease of preparation of $\mathrm{SiO}_{2}$ recommends this material-based shell for the production of high-quality core-shell nanostructures with customized properties.

\section{2. $\mathrm{TiO}_{2}$-Based Shells}

$\mathrm{TiO}_{2}$ is another type of shell-coating material that can be used to fabricate coreshell nanoparticles. Xue et al. [64] used it to improve the color stability of the resultant product. First, PS@TiO 2 and $\mathrm{Air} @ \mathrm{CTiO}_{2}$ core-shell nanoparticles were created. Then, liquid $\mathrm{NaOH}(5 \mathrm{wt} \%)$ was applied to purify the styrene (St) and methacrylic acids. This process was repeated three times before being placed in a refrigerator. These experiments were conducted using titanium butoxide (TBOT), acetic acid (99\%), ethanol, potassium persulfate, sulphuric acid (98\%), and hydrogen peroxide $\left(\mathrm{H}_{2} \mathrm{O}_{2}\right)(28-30 \%)$. In addition, deionized water was purified through a specialized water purification system possessing a resistivity in excess of $18 \mathrm{M} \Omega \cdot \mathrm{cm}$. Besides, other analytical-grade reagents were used without any further purification. Subsequently, the soap-free emulsion polymerization and sol-gel methods were used to create $\mathrm{PS}_{\mathrm{TiO}}$ spheres. Specifically, a hydrolysis reaction between TBOT and ethanol was performed for this purpose. PS ( $0.8 \mathrm{~g})$ was manufactured in the laboratory and redistributed into an acetonitrile $(10 \mathrm{~mL})$ and ethyl alcohol $(70 \mathrm{~mL})$ solution. Next, ammonia $(0.5 \mathrm{~mL})$ was added to the PS dispersion for half an hour (500 rpm). A solvent containing a specified quantity of TBOT $(2 \mathrm{~mL})$, acetonitrile $(10 \mathrm{~mL})$, and pure alcohol $(10 \mathrm{~mL})$ was added to the PS solution drop by drop and continuously stirred for $2 \mathrm{~h}$. The same process was repeated for 5, 10, and then $15 \mathrm{~h}$, resulting in the formation of

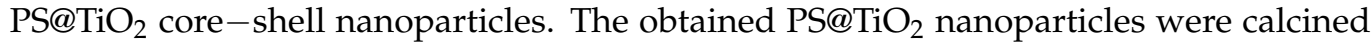

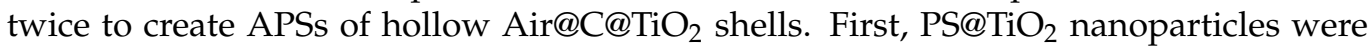
calcined at a rate of $1{ }^{\circ} \mathrm{C} / \mathrm{min}$ at $500{ }^{\circ} \mathrm{C}$ and then stored in a nitrogen atmosphere for $2 \mathrm{~h}$. The solutions were then left to cool down to room temperature, yielding dark Air@C@ $\mathrm{TiO}_{2}$ shells. In the next step, as-prepared cupped shells were subject to calcination at a rate of $1{ }^{\circ} \mathrm{C} / \mathrm{min}$ and at a temperature of $280^{\circ} \mathrm{C}$. The sample was kept under these conditions 
for $10 \mathrm{~min}$. The remaining products were left to cool down to room temperature naturally inside the furnace. The resultant dyes showed complete spherical Air@C@ $\mathrm{TiO}_{2}$ shells with suitable saturation levels. The same conditions were utilized to produce $\mathrm{PS}_{2} \mathrm{TiO}_{2}$ spheres of various sizes via the calcination process.

Sadeghi-Niaraki et al. [65] produced $\mathrm{Fe}_{2} \mathrm{O}_{3} @ \mathrm{TiO}_{2}$ nanoparticles using $\mathrm{TiO}_{2}$. A dualfunctional nanostructured $\mathrm{Fe}_{2} \mathrm{O}_{3} @ \mathrm{TiO}_{2}$ pigment (sometimes referred to as a cool pigment) with unique photocatalytic properties and NIR reflection was achieved. $\mathrm{Fe}_{2} \mathrm{O}_{3} @ \mathrm{TiO}_{2}$ nanoparticles were created using different proportions of $\mathrm{Fe}_{2} \mathrm{O}_{3} @ \mathrm{TiO}_{2}$ at $0.06,0.62$, and 1.24. Furthermore, a coprecipitation method was used in the presence of $\mathrm{Fe}^{3+}$ precursors to fabricate $\mathrm{Fe}_{2} \mathrm{O}_{3}$ nanoparticles. Next, the sol-gel technique was used to coat them in $\mathrm{TiO}_{2}$. To create $\mathrm{Fe}_{2} \mathrm{O}_{3} @ \mathrm{TiO}_{2}$ nanoparticles, various materials like ethanol, acetone, $\mathrm{NH}_{3}$, TBOT, and $\mathrm{Fe}_{2} \mathrm{O}_{3}$ were used. Various ratios of $\mathrm{Fe}_{2} \mathrm{O}_{3}: \mathrm{TiO}_{2}(0.02,0.06,1.0,0.62$, and 1.24) and different contents of $\mathrm{Fe}_{2} \mathrm{O}_{3}$ ( 0 for $0.05,0.05,0.05,0.5,1$, and $0 \mathrm{~g}$ ) were used. About $0.05 \mathrm{~g}$ of $\mathrm{Fe}_{2} \mathrm{O}_{3}$ was dispersed in solutions containing $25 \mathrm{~mL}$ of acetone, $25 \mathrm{~mL}$ of ethanol, and $0.15 \mathrm{~mL}$ of ammonia. To ensure the even dispersion of the solution, it was sonicated for $30 \mathrm{~min}$ before being supplemented with $3 \mathrm{~mL}$ of TBOT with intense stirring at $600 \mathrm{rpm}$. The reaction lasted for $2 \mathrm{~h}$, and the remaining products were centrifuged at $3000 \mathrm{rpm}$ and then rinsed with DI water, as well as ethanol. Eventually, they were left to air-dry at $80^{\circ} \mathrm{C}$ for $12 \mathrm{~h}$. The resultant $\mathrm{Fe}_{2} \mathrm{O}_{3} @ \mathrm{TiO}_{2}$ nanoparticles were then air-calcined for $2 \mathrm{~h}$ at $600{ }^{\circ} \mathrm{C}$. Figure 4 depicts the schematic presentation of the $\mathrm{Fe}_{2} \mathrm{O}_{3} @ \mathrm{TiO}_{2}$ core-shell particle fabrication process.

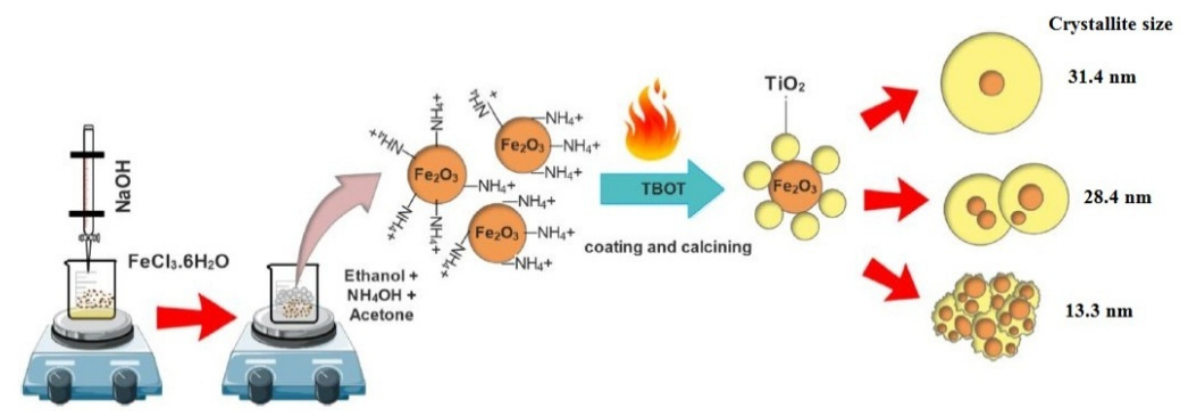

Figure 4. Schematic illustration of the $\mathrm{Fe}_{2} \mathrm{O}_{3} @ \mathrm{TiO}_{2}$ core-shell particles' preparation and formation [65].

Dandan et al. [66] used the hydrothermal technique to make homogeneous $\alpha-\mathrm{Fe}_{2} \mathrm{O}_{3} @ \mathrm{TiO}_{2}$ core-shell nanoparticles. In this process, the photocatalytic performance was found to be enhanced when $\mathrm{TiO}_{2}$ was used. To prepare the $\alpha-\mathrm{Fe}_{2} \mathrm{O}_{3} @ \mathrm{TiO}_{2}$ particles, $\alpha-\mathrm{FeOOH}$ nanoparticles were subjected to a hydrothermal process. To grow the homogeneous $\mathrm{TiO}_{2}$ shell, TBOT was employed, and a sol-gel reaction was performed for $24 \mathrm{~h}$ at $45^{\circ} \mathrm{C}$. A two-stage solution preparation process was performed to produce $\alpha-\mathrm{Fe}_{2} \mathrm{O}_{3} @$ amorphous $\mathrm{TiO}_{2}$ core-shell particles. The first stage involved the preparation of $\alpha-\mathrm{Fe}_{2} \mathrm{O}_{3}$ nanoparticles using the surfactant-free solvothermal method [67]. In this method, $14.5 \mathrm{~mL}$ of deionized water was magnetically stirred to dissolve $0.055 \mathrm{~mol}$ of $\mathrm{FeCl}_{3} \cdot 6 \mathrm{H}_{2} \mathrm{O}$, producing a yellowish substance. This substance was placed onto a Teflon-lined autoclave capable of holding $20.0 \mathrm{~mL}$ and left for $4 \mathrm{~h}$ in an electric oven at $180^{\circ} \mathrm{C}$. Once the reaction was finished, the autoclave was turned off and left to cool down to room temperature. The resultant specimen was centrifuged to achieve red precipitate, which was rinsed in distilled water and pure ethanol before being left to dry at room temperature. Then, about $0.02 \mathrm{~g}$ of the $\alpha-\mathrm{Fe}_{2} \mathrm{O}_{3}$ nanoparticles were placed in $30 \mathrm{~mL}$ of ethanol to get a suspension. Next, an ethanol mixture containing tetrabutyl titanate $\left(\mathrm{Ti}(\mathrm{BuO})_{4}\right)\left(\right.$ volume ratio $\left.\mathrm{V}_{\mathrm{Ti}(\mathrm{BuO})_{4}} / \mathrm{V}_{\text {ethanol }}=0.3 \mathrm{~mL} / 10 \mathrm{~mL}\right)$ was added into the suspension and stirred intensely for $2 \mathrm{~h}$. Thereafter, a mixture made from $0.2 \mathrm{~mL}$ of water and $5.0 \mathrm{~mL}$ of ethanol was added to the solution. Subsequently, the solution was stirred for an extra $3 \mathrm{~h}$ at room temperature before being centrifuged to separate the precipitates. Later, the precipitates were washed multiple times with water 
and pure ethanol and left to air-dry. Finally, the obtained $\alpha-\mathrm{Fe}_{2} \mathrm{O}_{3} @ \mathrm{TiO} \mathrm{O}_{2}$ core-shell particles were placed in a muffle furnace and heated at $450{ }^{\circ} \mathrm{C}$ for $2 \mathrm{~h}$ for calcination.

Using a chemical vapor deposition method, Wang et al. [67] produced $\beta-\mathrm{FeOOH}$ nanorod arrays. This also enhanced the process of separating photogenerated electron hole pairs using simulated solar light. First, the FTO substrates coated with $\beta$-FeOOH nanorod arrays were placed in the PECVD chamber. Then, a glass flask containing a titanium precursor was attached to the reaction system. To ensure the sufficiency of the vapor pressure of the precursor, the glass flask was heated at $70{ }^{\circ} \mathrm{C}$. Subsequently, the chamber pressure was reduced to less than $0.5 \mathrm{~Pa}$, and $20 \mathrm{sccm}$ of $\mathrm{O}_{2}$ was added to the chamber. The PECVD approach (100 W of plasma power with different durations) was used to produce $\beta$-FeOOH nanorod arrays with varying $\mathrm{TiO}_{2}$ shell thicknesses. After the post-annealing treatment for two hours at $750{ }^{\circ} \mathrm{C}$, the $\mathrm{Fe}_{2} \mathrm{O}_{3} @ \mathrm{TiO}_{2}$ core-shell nanorod arrays were obtained. Zhang et al. [68] also used this approach to fabricate $\alpha-\mathrm{Fe}_{2} \mathrm{O}_{3} @ \mathrm{TiO}_{2}$ particles with porous structures, wherein the main objective was to improve the photocatalytic activity of the achieved products.

To create highly dispersed $\mathrm{NiTiO}_{3} @ \mathrm{TiO}_{2}$ yellow pigments in a core-shell form, the precursors acquired from the $\mathrm{Ni}^{2+}$ present on the surface of $\mathrm{TiO}_{2}$ particles $[69,70]$ were calcined. The first step of this two-stage process involved the controlled hydrolysis of TBOT (tetra butyl titanate). In this process, $300 \mathrm{~mL}$ of ethanol and $1.0 \mathrm{~mL}$ of $\mathrm{KCl}$ solution $(0.4 \mathrm{mM})$ were mixed and stirred for $20 \mathrm{~min}$, and then, $5 \mathrm{~mL}$ of TBOT was added with continual stirring for $10 \mathrm{~min}$. After stirring was discontinued, the reactions were completed, and the resultant powder was obtained via centrifugation. The obtained powder was washed multiple times with water and ethanol. The as-prepared white powder was heated in a vacuum oven $\left(60{ }^{\circ} \mathrm{C}\right)$ for $12 \mathrm{~h}$ to dry. Second, $0.2 \mathrm{~g}$ of as-prepared $\mathrm{TiO}_{2}$ powder was dispersed into $200 \mathrm{~mL}$ of distilled water, followed by ultrasonication. Next, $\mathrm{Ni}$ $\left(\mathrm{NO}_{3}\right)_{2} \cdot 6 \mathrm{H}_{2} \mathrm{O}$ and $\mathrm{CO}\left(\mathrm{NH}_{2}\right)_{2}$ were added to the suspension, and the solution was stirred for $30 \mathrm{~min}$. A water bath at $80{ }^{\circ} \mathrm{C}$ was then used to heat the suspension following continual stirring for $6 \mathrm{~h}$. After cooling, the suspension was centrifuged to collect the precipitates. The precipitates were then washed multiple times with water and ethanol and stored at $60{ }^{\circ} \mathrm{C}$ overnight to produce green powders. Furthermore, the $\mathrm{NiTiO}_{3} @ \mathrm{TiO}_{2}$ yellow pigments were produced by calcinating it for three hours at different temperatures in the range of $500-950{ }^{\circ} \mathrm{C}$. The samples were labeled as $\mathrm{NiTiO}_{3-\mathrm{x}} @ \mathrm{TiO}_{2}$ (x-range was from 0.25 to $1.0 \mathrm{wt} \%)$.

Table 1. Core-shell nanostructure pigment synthesis methods.

\begin{tabular}{|c|c|c|c|c|}
\hline No. & Core-Shell NPs & Synthesis Method & Synthesis Details (Brief) & Ref. \\
\hline 1 & $\mathrm{Fe}_{2} \mathrm{O}_{3} @ \mathrm{SiO}_{2}$ & Sol-gel method & $\begin{array}{l}\text { The sol-gel method to hydrolyze tetraethyl orthosilicate } \\
\text { (TEOS) in an attempt to cover iron oxide nanoparticles in } \\
\text { uniform shells. By changing the sol-gel precursor } \\
\text { concentration, it was possible to modify the thickness of } \\
\text { these silica shells. }\end{array}$ & [53] \\
\hline 2 & $\mathrm{CeO}_{2} @ \mathrm{SiO}_{2}$ & Sol-gel method & $\begin{array}{l}\text { To synthesize the } \mathrm{SiO}_{2} \text {-covered } \mathrm{CeO}_{2} \text { nanoparticles, } \\
\text { cyclohexane ( } 99 \% \text { ) was applied as the organic phase in } \\
\text { order to perform reverse micelles on polyoxyethylene } \\
\text { (15) cetylether. }\end{array}$ & [54] \\
\hline 2 & $\begin{array}{c}\mathrm{Sr}^{2+} \text {-doped } \\
\gamma-\mathrm{Ce}_{2} \mathrm{~S}_{3} @ \mathrm{c}-\mathrm{SiO}_{2}\end{array}$ & Stöber method & $\begin{array}{c}\text { Amorphous } \mathrm{SiO}_{2}\left(\mathrm{a}-\mathrm{SiO}_{2}\right) \text { sol and } \mathrm{Sr}^{2+} \text {-doped } \mathrm{CeO}_{2} \text { were } \\
\text { employed as precursors. The original materials used in } \\
\text { this experiment were } \mathrm{Si}\left(\mathrm{OC}_{2} \mathrm{H}_{5}\right)_{4}(\mathrm{TEOS}), \mathrm{Sr}\left(\mathrm{NO}_{3}\right)_{2} \\
\mathrm{Ce}\left(\mathrm{NO}_{3}\right)_{3} \cdot 6 \mathrm{H}_{2} \mathrm{O},\left(\mathrm{NH}_{4}\right)_{2} \mathrm{CO}_{3} \text {, ammonia water, and } \\
\text { ethanol. }\end{array}$ & [57] \\
\hline
\end{tabular}


Table 1. Cont.

\begin{tabular}{|c|c|c|c|c|}
\hline No. & Core-Shell NPs & Synthesis Method & Synthesis Details (Brief) & Ref. \\
\hline 3 & $\mathrm{Zn}_{1-\mathrm{x}} \mathrm{Co}_{\mathrm{x}} \mathrm{O} @ \mathrm{SiO}_{2}$ & Stöber method & $\begin{array}{l}\text { A polyol process was used to form } \mathrm{ZnO} \text { doped with } \\
\mathrm{Co}^{2+} \text {, a well-known substitute for chromium-based } \\
\text { inorganic pigments. Additionally, to source the zinc and } \\
\text { cobalt needed in the experiment, zinc acetate dihydrate } \\
\left(\mathrm{Zn}\left(\mathrm{CH}_{3} \mathrm{OO}\right)_{2} \cdot 2 \mathrm{H}_{2} \mathrm{O}\right) \text { and cobalt nitrate } \\
\left(\mathrm{Co}\left(\mathrm{NO}_{3}\right)_{2} \cdot 6 \mathrm{H}_{2} \mathrm{O}\right) \text { were employed, with diethylene } \\
\text { glycol }\left(\mathrm{H}_{10} \mathrm{C}_{4} \mathrm{O}_{3}\right) \text { being used as a template. }\end{array}$ & [58] \\
\hline 4 & $\mathrm{Fe}_{2} \mathrm{O}_{3} @ \mathrm{SiO}_{2}$ & $\begin{array}{l}\text { Hydrothermal and } \\
\text { Stöber methods }\end{array}$ & $\begin{array}{l}\text { The Stöber method was carried out to fabricate the } \\
\text { reddish pigments using } \alpha-\mathrm{Fe}_{2} \mathrm{O}_{3} \text { as chromophore } \\
\text { particles and tetraethoxysilane (TEOS, AR) to source the } \\
\text { silica. }\end{array}$ & [28] \\
\hline 5 & $\alpha-\mathrm{Fe}_{2} \mathrm{O}_{3} @ \mathrm{SiO}_{2}$ & Sol-gel method & $\begin{array}{l}\text { The original materials used in the process were } \\
\left.\mathrm{FeCl}_{3} \cdot 6 \mathrm{H}_{2} \mathrm{O}(97 \%) \text {, tetraethylorthosilicate (TEOS } 99.99 \%\right) \text {, } \\
\text { cetyltrimethylammonium bromide (CTAB, } 99 \%) \text {, and } \\
\mathrm{NH}_{4} \mathrm{OH}(28 \% \text { in water, } 99.99 \%) \text {, which were obtained } \\
\text { from Aldrich. Additionally, DI water was employed. }\end{array}$ & [60] \\
\hline 6 & $\mathrm{ZnS@SiO} 2$ & $\begin{array}{c}\text { Homogeneous } \\
\text { deposition method }\end{array}$ & $\begin{array}{c}\mathrm{ZnS@SiO} \text { core-shell nanoparticles were produced } \\
\text { through a homogeneous deposition method in which } \\
\text { deionized water }(1 \mathrm{~mL}) \text { and ammonia }(0.5 \mathrm{~mL}) \text { were } \\
\text { placed into a 30-mL colloidal solution of } \mathrm{ZnS} \\
(0.5-2 \mathrm{wt} \%) .\end{array}$ & [61] \\
\hline 7 & $\gamma-\mathrm{Ce}_{2} \mathrm{~S}_{3} @ \mathrm{SiO}_{2}$ & Stöber method & $\begin{array}{c}\text { The } \gamma-\mathrm{Ce}_{2} \mathrm{~S}_{3} \text { red pigments with a silica layer using the } \\
\text { Stöber technique combined with hydrogen-argon } \\
\text { atmosphere heat treatment }\left(700^{\circ} \mathrm{C}\right) .\end{array}$ & [62] \\
\hline 8 & $\alpha-\mathrm{Fe}_{2} \mathrm{O}_{3} @ \mathrm{SiO}_{2}$ & Sol-gel process & $\begin{array}{l}\text { Silica nanoparticles were used in a sol-gel process to coat } \\
\text { the natural pigment of hematite (red ocher, } \alpha-\mathrm{Fe}_{2} \mathrm{O}_{3} \text { ), the } \\
\text { objective of which was to produce a long-lasting } \\
\text { hematite pigment of the } \mathrm{Fe}_{2} \mathrm{O}_{3} @ \mathrm{SiO}_{2} \text { nanocomposite } \\
\text { that could be used to preserve artefacts. To achieve this, } \\
2.2 \mathrm{wt} \% \text { of pure } \alpha-\mathrm{Fe}_{2} \mathrm{O}_{3} \text { in the silica sol was charged } \\
\text { over a period of time and continually stirred. }\end{array}$ & [63] \\
\hline 9 & $\begin{array}{l}\mathrm{PS} @ \mathrm{TiO}_{2} \text { and } \\
\text { Air@C@ } \mathrm{TiO}_{2}\end{array}$ & $\begin{array}{l}\text { Soap-free emulsion } \\
\text { polymerization and } \\
\text { sol-gel methods }\end{array}$ & $\begin{array}{l}\text { The experiments were conducted using titanium } \\
\text { butoxide (TBOT), acetic acid (99\%), ethanol, potassium } \\
\text { persulfate, sulphuric acid (98\%), and hydrogen peroxide } \\
\left(\mathrm{H}_{2} \mathrm{O}_{2}\right)(28-30 \%) .\end{array}$ & [64] \\
\hline 10 & $\mathrm{Fe}_{2} \mathrm{O}_{3} @ \mathrm{TiO}_{2}$ & Sol-gel method & $\begin{array}{l}\text { To create } \mathrm{Fe}_{2} \mathrm{O}_{3} @ \mathrm{TiO}_{2} \text { nanoparticles, various materials } \\
\text { were used, including ethanol, acetone, } \mathrm{NH}_{3} \text {, TBOT, and } \\
\mathrm{Fe}_{2} \mathrm{O}_{3} \text {. The following ratios of } \mathrm{Fe}_{2} \mathrm{O}_{3}: \mathrm{TiO}_{2} \text { were also } \\
\text { used: } 0.02,0.06,1.0,0.62,1.24 \text {, and } 0 \text { for } 0.05,0.05,0.05 \text {, } \\
0.5,1 \text {, and } 0 \mathrm{~g} \text { of } \mathrm{Fe}_{2} \mathrm{O}_{3} \text {, respectively. Usually, } 0.05 \mathrm{~g} \text { of } \\
\mathrm{Fe}_{2} \mathrm{O}_{3} \text { are dispersed in solutions containing } 25 \mathrm{~mL} \text { of } \\
\text { acetone, } 25 \mathrm{~mL} \text { of ethanol, and } 0.15 \mathrm{~mL} \text { of ammonia. }\end{array}$ & [65] \\
\hline 11 & $\alpha-\mathrm{Fe}_{2} \mathrm{O}_{3} @ \mathrm{TiO}_{2}$ & $\begin{array}{l}\text { Hydrothermal } \\
\text { method/sol-gel } \\
\text { method }\end{array}$ & $\begin{array}{l}\text { The } \alpha \text {-FeOOH nanoparticles were subjected to a } \\
\text { hydrothermal process. Additionally, to create the } \\
\text { homogeneous } \mathrm{TiO}_{2} \text { shell, a TBOT was employed, and a } \\
\text { sol-gel reaction was performed for } 24 \mathrm{~h} \text { at } 45^{\circ} \mathrm{C} \text {. }\end{array}$ & [66] \\
\hline 12 & $\begin{array}{c}\beta-\mathrm{FeOOH} \\
\text { nanorod@ } @ \mathrm{TiO}_{2}\end{array}$ & $\begin{array}{l}\text { Plasma-assisted } \\
\text { chemical vapor } \\
\text { deposition }\end{array}$ & $\begin{array}{l}\text { A two-stage solution preparation process was then } \\
\text { carried out to produce } \alpha-\mathrm{Fe}_{2} \mathrm{O}_{3} @ \text { amorphous } \mathrm{TiO}_{2} \\
\text { core-shell particles, the first stage of which involved } \\
\text { preparing } \alpha-\mathrm{Fe}_{2} \mathrm{O}_{3} \text { nanoparticles through the } \\
\text { performance of a surfactant-free solvothermal method. }\end{array}$ & [67] \\
\hline
\end{tabular}


Table 1. Cont.

\begin{tabular}{|c|c|c|c|c|}
\hline No. & Core-Shell NPs & Synthesis Method & Synthesis Details (Brief) & Ref. \\
\hline 13 & $\alpha-\mathrm{Fe}_{2} \mathrm{O}_{3} @ \mathrm{TiO}_{2}$ & $\begin{array}{l}\text { Plasma-assisted } \\
\text { chemical vapor } \\
\text { deposition }\end{array}$ & $\begin{array}{c}\text { Similar to the above approach in point } 12 \text {, the } \\
\alpha-\mathrm{Fe}_{2} \mathrm{O}_{3} @ \mathrm{TiO}_{2} \text { particles were fabricated with porous } \\
\text { structures, the key objective of which was to improve the } \\
\text { photocatalytic activity. }\end{array}$ & {$[68]$} \\
\hline 14 & $\mathrm{NiTiO}_{3} @ \mathrm{TiO}_{2}$ & Sol-gel method & $\begin{array}{l}\text { First stage, } 300 \mathrm{~mL} \text { of ethanol and } 1.0 \mathrm{~mL} \text { of } \mathrm{KCl} \text { liquid } \\
\text { solution }(0.4 \mathrm{mM}) \text { were mixed and stirred for } 20 \mathrm{~min} \text {; } \\
\text { after which, } 5 \mathrm{~mL} \text { of TBOT was added. It was then } \\
\text { stirred for } 10 \mathrm{~min} \text {. Secondly, } 0.2 \text { gas-prepared } \mathrm{TiO}_{2} \\
\text { powder was dispersed into } 200 \mathrm{~mL} \text { of distilled water } \\
\text { ultrasonically, and then, } \mathrm{Ni}\left(\mathrm{NO}_{3}\right)_{2} \cdot 6 \mathrm{H}_{2} \mathrm{O} \text { and } \mathrm{CO}\left(\mathrm{NH}_{2}\right)_{2} \\
\text { were added to the suspension, and the solution was } \\
\text { stirred for } 30 \mathrm{~min} \text {. }\end{array}$ & {$[69,70]$} \\
\hline
\end{tabular}

\section{Core Materials}

\subsection{Ferric Oxide}

The inorganic compound ferric oxide (also known as iron oxide) represented by the formula $\mathrm{Fe}_{2} \mathrm{O}_{3}$ is one of the three oxides of iron, along with iron (II) oxide ( $\mathrm{FeO}$ ) (relatively rare compound) and iron (II, III) oxide $\left(\mathrm{Fe}_{3} \mathrm{O}_{4}\right)$, a naturally occurring substance found in mineral magnetite. $\mathrm{Fe}_{2} \mathrm{O}_{3}$ is also known as hematite, which is a primary material used to source iron in the steel industry. Generally, iron oxides, including $\mathrm{FeO}, \alpha-\mathrm{Fe}_{2} \mathrm{O}_{3}$, $\gamma-\mathrm{Fe}_{2} \mathrm{O}_{3}$, and $\mathrm{Fe}_{3} \mathrm{O}_{4}$, are applied in cosmetics, electronic materials, pigments, abrasives, and coatings [71-73]. $\alpha-\mathrm{Fe}_{2} \mathrm{O}_{3}$ is an important inorganic red pigment and is safe to use because of its nontoxic nature [26]. Over the last few years, an increasing number of researchers have been investigating nanoscale magnetic materials due to their wide array of potential applications, including information storage, magnetic refrigeration, separation, magneto-optical solid devices, and magnetic resonance imaging, in addition to many conventional applications (i.e., plastic reinforcement and fluid rheological additives). These nanoparticles are also suitable for making high-performance devices. Various chemical techniques have been used to fabricate these nanoparticles with narrow-sized distributions and tailored morphologies, as well as structures. These techniques include flame-spray pyrolysis, sol-gel, hot-soap, plasma chemical vapor deposition (CVD), microemulsion, and electrospray pyrolysis.

Many researchers [26,74-77] have used hematite $\left(\mathrm{Fe}_{2} \mathrm{O}_{3}\right)$ to produce $\mathrm{Fe}_{2} \mathrm{O}_{3} @ \mathrm{SiO}_{2}$ pigments. For instance, an $\alpha-\mathrm{Fe}_{2} \mathrm{O}_{3} @ \mathrm{SiO}_{2}$ composite core-shell was produced to serve as a protective coating for pigments [63]. Ri et al. [77] used core-shell technology to enhance the thermal properties of pigments by coating them with $\mathrm{Fe}_{2} \mathrm{O}_{3}$ nanoparticles. Silica was used to coat both $\beta-\mathrm{FeOOH}$ and $\alpha-\mathrm{Fe}_{2} \mathrm{O}_{3}$ nanoparticles with tetraethylorthosilicate (TEOS), and cetyltrimethylammonium bromide (CTAB) was used as a surface modifier. The physical properties of the two samples were compared. $\mathrm{Fe}_{3} \mathrm{O}_{4} @ \mathrm{SiO}_{2}$ nanoparticles were prepared [76] using the coprecipitation method. In the air atmosphere, a $\mathrm{FeCl}_{3}(0.5 \mathrm{M})$ and $\mathrm{FeSO}_{4}(0.5 \mathrm{M})$ solution with a molar ratio of 1.75 to 1 was produced to make magnetic nanoparticles (MNPs). After this, $10 \mathrm{~mL}$ of liquid ammonia was added to the mixture and stirred intensely, and extra ammonia was added until a $\mathrm{pH}$ value of 9 was achieved. The solution was then stirred for another $30 \mathrm{~min}$. Lastly, magnetite was used to obtain the precipitates, which were rinsed multiple times with deionized water and alcohol to reduce the $\mathrm{pH}$ to 7.0. To adjust the surface of the $\mathrm{Fe}_{3} \mathrm{O}_{4}$ particles, MNPs were reacted with sodium citrate. In this process, $1 \mathrm{~g}$ of $\mathrm{Fe}_{3} \mathrm{O}_{4} \mathrm{MNPs}$ was combined with $200 \mathrm{~mL}$ of sodium citrate $(0.5 \mathrm{M})$ in a flask. Then, the solution was ultrasonically irradiated for $30 \mathrm{~min}$ in order to bring the MNPs together. Next, it was kept at $60.8^{\circ} \mathrm{C}$ and stirred whilst being protected by the air atmosphere. Magnetite was then used to collect the precipitates, which were rinsed in acetone to eliminate any remaining sodium citrate. The new MNPs with modified surfaces were dispersed again in $100 \mathrm{~mL}$ of deionized water to create the ferrofluids (FF). 
Subsequently, $2 \mathrm{~mL}$ of the FF was placed in $50 \mathrm{~mL}$ of deionized water and ultrasonically irradiated for $30 \mathrm{~min}$. The obtained suspension was added to $150 \mathrm{~mL}$ of ethanol plus $5 \mathrm{~mL}$ of $\mathrm{NH}_{3} \cdot \mathrm{H}_{2} \mathrm{O}$ and stirred intensively at $40{ }^{\circ} \mathrm{C}$. Later, $4 \mathrm{~mL}$ of TEOS were added to the solution for $12 \mathrm{~h}$ to complete the reaction. Lastly, the solution was filtrated to collect the precipitates. The collected precipitates was rinsed with ethanol and deionized water before being left to dry for $12 \mathrm{~h}$ in a vacuum.

Chen et al. [28] used $\mathrm{Fe}_{2} \mathrm{O}_{3}$ as the core material to synthesize $\mathrm{Fe}_{2} \mathrm{O}_{3} @ \mathrm{SiO}_{2}$ core-shell particles. A hydrothermal process was used to fabricate the highly dispersed $\alpha-\mathrm{Fe}_{2} \mathrm{O}_{3}$ nanoparticles. First, $2.89 \mathrm{~g}$ of $\mathrm{FeCl}_{3} \cdot 6 \mathrm{H}_{2} \mathrm{O}$ and $3.39 \mathrm{~g}$ of $\mathrm{Na}_{2} \mathrm{CO}_{3}$ were placed in $80 \mathrm{~mL}$ of deionized water with constant stirring. This produced an orange solution that was stirred for $15 \mathrm{~min}$ before being placed in a stainless-steel autoclave of 100-mL capacity and maintained at $180^{\circ} \mathrm{C}$ for $8 \mathrm{~h}$, then left to cool down to room temperature. The obtained mixture was centrifuged to get a red precipitate, which was washed three times in water and deionized water. The sample was then stored at $70{ }^{\circ} \mathrm{C}$ for $5 \mathrm{~h}$ to let it dry.

Repeated experiments verified that iron oxide can be mixed with other inorganic elements to form core-shell particles. Rahimi et al. [78] used the hydrothermal process to fabricate nano-hollow $\mathrm{Zn}-\mathrm{Fe}_{2} \mathrm{O}_{4}$ microspheres where the chemical reagents of $\mathrm{ZnCl}_{2}$, $\mathrm{FeCl}_{3} \cdot 6 \mathrm{H}_{2} \mathrm{O}$, and ammonium acetate were mixed. In this process, a mechanical stirrer was used to mix the solution containing $70 \mathrm{~mL}$ of ethylene glycol, iron (III) chloride, and zinc chloride for further purification. About $2.312 \mathrm{~g}$ of $\mathrm{NH}_{4} \mathrm{Ac}$ was added to the mixture with constant stirring, wherein the solution slowly turned a dark-yellow color. The obtained solution was sonicated for $40 \mathrm{~min}$, followed by oven heating at $215^{\circ} \mathrm{C}$ for $4 \mathrm{~h}$ in order to produce some black precipitates. Finally, the $\mathrm{ZnO}$ nanoparticles were immobilized on the surface of the $\mathrm{Zn}$-ferrite spheres to form $\mathrm{Zn}-\mathrm{Fe}_{2} \mathrm{O}_{4} @ \mathrm{ZnO}$ core-shell structured spheres, which was achieved through a sol-gel approach.

\subsection{Silver}

In recent times, many researchers have been focusing on the syntheses and characterizations of various metallic nanoparticles (NPs) to serve as core-shell pigments for diverse industrial applications. These NPs possess many unusual properties, including an enhanced resistance to harsh environments and increased color stability desirable for widespread applications. Silver $(\mathrm{Ag})$ is an example of a metallic nanoparticle that has been widely used as a core-shell composite in the manufacturing industry. In an attempt to identify a material that can be used in marine settings to prevent corrosion, Zhang et al. [79] produced $\mathrm{Ag} @ \mathrm{SiO}_{2}$ core-shell nanoparticles. In this process, $5 \mathrm{~mL}$ of $0.1-\mathrm{M}$ liquid hydrazine was immersed in $400 \mathrm{~mL}$ of aqueous solution $(0.146 \mathrm{~g}, \mathrm{C} 16 \mathrm{TMABr})$ and stirred vigorously at room temperature for $2 \mathrm{~min}$; after which, $10 \mathrm{~mL}$ of $0.05-\mathrm{M} \mathrm{AgNO}_{3}$ solution was added to the solution drop by drop to prepare the Ag colloids. This caused the solution to turn a reddish-brown color. Thereafter, $100 \mathrm{~mL}$ of ethanol and $4 \mathrm{~mL}$ of liquid ammonia $(25 \mathrm{wt} \%)$ were added to the silver colloids. Finally, $0.5 \mathrm{~mL}$ of TEOS was put into the solution and stirred for two more hours to produce a suspension containing monodisperse $\mathrm{Ag} @ \mathrm{SiO}_{2}$ core-shell nanoparticles. Figure 5 presents the various steps of the preparation.

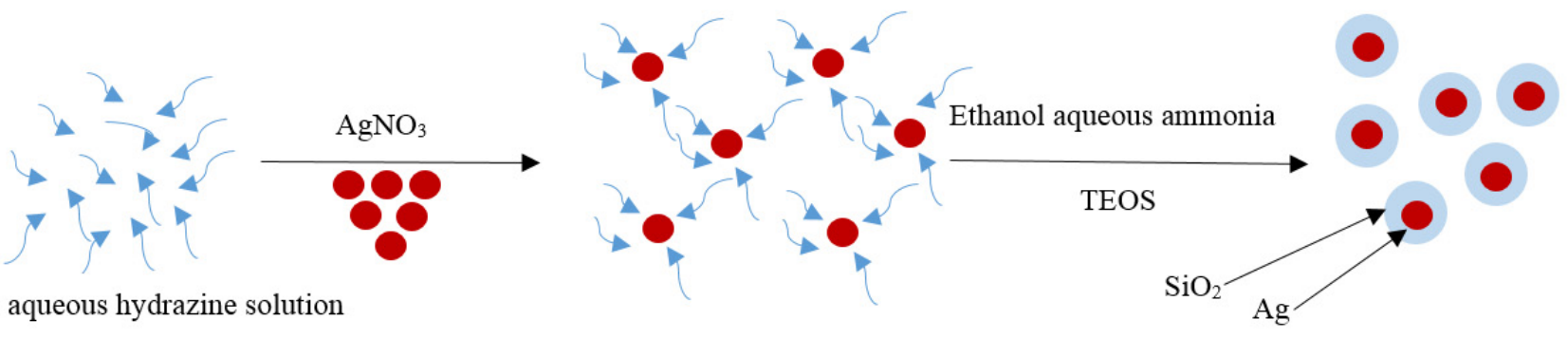

Figure 5. Schematic illustration for $\mathrm{Ag} / \mathrm{SiO}_{2}$ core-shell nanoparticle synthesis. 


\subsection{Ceric Oxide}

Ceric oxide is a pale-yellow / white powder derived from the rare-earth metal cerium and has the chemical formula $\mathrm{CeO}_{2}$. It an important commercial product and plays a significant role in purifying elements from their ores. In recent years, increasing research focus has been paid to produce $\mathrm{CeO}_{2} @ \mathrm{SiO}_{2}$ core-shell nanoparticles due to their several benefits [80,81]. Tago et al. [54] implemented a $\mathrm{CeO}_{2}$-based core to fabricate a core-shell nanoparticle. Yu et al. [43] successfully produced different g-Ce $\mathrm{C}_{3} @ \mathrm{SiO}_{2}$ pigments through a process of sulfurizing their existing $\mathrm{CeO}_{2}$ coatings with $\mathrm{SiO}_{2}$ shells of varying thicknesses. In this preparation method, $2 \mathrm{~g}$ of $\mathrm{Ce}\left(\mathrm{NO}_{3}\right)_{3} \cdot 6 \mathrm{H}_{2} \mathrm{O}$ was ultrasonically dissolved in $2 \mathrm{~mL}$ of deionized water in order to create the $\mathrm{CeO}_{2}$ nanoparticles, and then, $2 \mathrm{~mL}$ of $\mathrm{CH}_{3} \mathrm{COOH}$ and $60 \mathrm{~mL}$ of glycol were added. The whole mixture was stirred for $30 \mathrm{~min}$ to produce a homogeneous solution and then placed in a sealed Teflon-lined stainless-steel autoclave for $200 \mathrm{~min}$, followed by a heat treatment at $180^{\circ} \mathrm{C}$. The obtained mixture was centrifuged to separate the precipitates, followed by rinsing with ethanol and water and air-drying at $60{ }^{\circ} \mathrm{C}$. Figure 6 shows the process of coating $\mathrm{CeO}_{2}$ with $\mathrm{SiO}_{2}$ using the sol-gel technique.

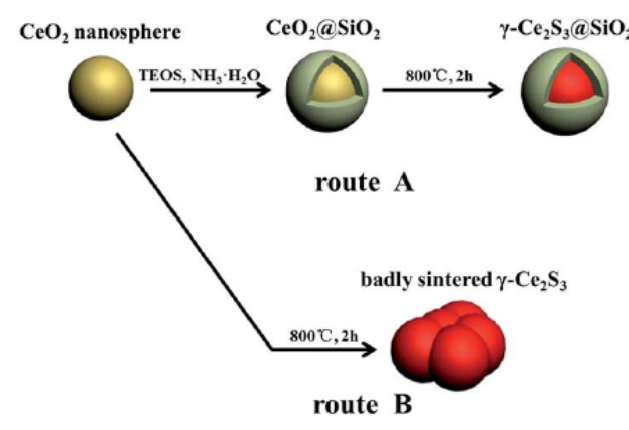

Figure 6. Formation of g- $\mathrm{Ce}_{2} \mathrm{~S}_{3} @ \mathrm{SiO}_{2}$ nanoparticles [43].

Many studies were conducted to wrap the pigments in a clear material to enhance the temperature stability and antioxidant properties of the $\gamma-\mathrm{Ce}_{2} \mathrm{~S}_{3}$ pigments. For instance, an amorphous $\mathrm{SiO}_{2}\left(\mathrm{a}-\mathrm{SiO}_{2}\right)$-coated $\gamma-\mathrm{Ce}_{2} \mathrm{~S}_{3}\left(\gamma-\mathrm{Ce}_{2} \mathrm{~S}_{3} @ \mathrm{a}-\mathrm{SiO}_{2}\right)$ was produced [82]. Chen et al. were able to raise the anti-oxidization temperature of the $\gamma-\mathrm{Ce}_{2} \mathrm{~S}_{3} @ \mathrm{a}-\mathrm{SiO}_{2}$ pigments to $450{ }^{\circ} \mathrm{C}$ [42]. Despite the fact that coating the surface of $\gamma-\mathrm{Ce}_{2} \mathrm{~S}_{3}$ pigments with $\mathrm{SiO}_{2}$ can enhance the pigments' temperature stability, the extent of this enhancement is still limited, which may be due to the low density of the a- $\mathrm{SiO}_{2}$ cladding layer. An alternative to this would be to coat the $\gamma-\mathrm{Ce}_{2} \mathrm{~S}_{3}$ pigments with a dense crystal $\mathrm{SiO}_{2}\left(\mathrm{c}-\mathrm{SiO}_{2}\right)$ layer, which would significantly improve the temperature stability of $\gamma-\mathrm{Ce}_{2} \mathrm{~S}_{3}$. In this rationale, $\mathrm{Li}$ et al. [57] used $\mathrm{Ce}_{2} \mathrm{~S}_{3} @ \mathrm{SiO}_{2}$ composites to successfully increase the temperature and acid stability of red pigments.

\subsection{Cetrimonium Bromide}

Cetrimonium bromide (CTAB) has been widely applied to fabricate nanoparticles and pigments. An experiment was performed [83] using the electrostatic self-assembly technique to create yellow $\mathrm{SiO}_{2}$ /Hansa pigment composite particles in a liquid solution. In this method, cetyltrimethylammonium bromide served as the coupling agent that positively charged the yellow pigment particles. Next, the particles were coated with a thin layer of $\mathrm{SiO}_{2}$ through the hydrolysis of $\mathrm{Na}_{2} \mathrm{SiO}_{3}$, which improved their charge load and optical and mechanical properties. The process of coating colloids with silica is generally two-fold. The first step usually involves the adsorbtion of CTAB and growth of the silica shell following the hydrolysis of $\mathrm{Na}_{2} \mathrm{SiO}_{3}$.

Figure 7 shows the process of synthesis. First, a glass of 500-mL volume was filled with a solution containing $0.18 \mathrm{~g}$ of $\mathrm{CTAB}$ and $150 \mathrm{~g}$ of water. Then, the mixture was stirred for $10 \mathrm{~min}$ at room temperature to form the CTAB solution. About $1.0 \mathrm{~g}$ of organic pigment was subsequently added to the CTAB solution and stirred ultrasonically for $60 \mathrm{~min}$ to create a stable organic pigment suspension. CTAB thus served as the dispersing and coupling 
agent. Once the yellow pigments were added to the $\mathrm{CTAB}$ solution, the system temperature was increased to $92{ }^{\circ} \mathrm{C}$. Thereafter, $20 \mathrm{~mL}$ of $\mathrm{Na}_{2} \mathrm{SiO}_{3}$ solution $\left(3.5 \mathrm{~g}\right.$ of $\left.\mathrm{Na}_{2} \mathrm{SiO}_{3} \cdot 9 \mathrm{H}_{2} \mathrm{O}\right)$ and $40 \mathrm{~mL}$ of $\mathrm{H}_{2} \mathrm{SO}_{4}$ solution (1.2 $\mathrm{g}$ of $\mathrm{H}_{2} \mathrm{SO}_{4}$ ) were placed into the pigment emulsion drop by drop, followed by the addition of the $\mathrm{Na}_{2} \mathrm{SiO}_{3}$ solution (at a $\mathrm{pH}$ of 9). Then, the $\mathrm{pH}$ of the $\mathrm{H}_{2} \mathrm{SO}_{4}$ solution was increased to 9 to10. It was very important to keep the time interval between the two different drops over $5 \mathrm{~s}$. The entire process took approximately $1 \mathrm{~h}$ to complete. Later, the temperature and reaction conditions were kept the same for another $5 \mathrm{~h}$. Finally, the $\mathrm{H}_{2} \mathrm{SO}_{4}$ solution was utilized to reduce the $\mathrm{pH}$ to 2 to 3 and was kept the same for $2 \mathrm{~h}$. The resulting solution was centrifuged to obtain the precipitates, which were then washed multiple times with pure ethanol and placed in a vacuum at $60{ }^{\circ} \mathrm{C}$ for $4 \mathrm{~h}$ to dry.

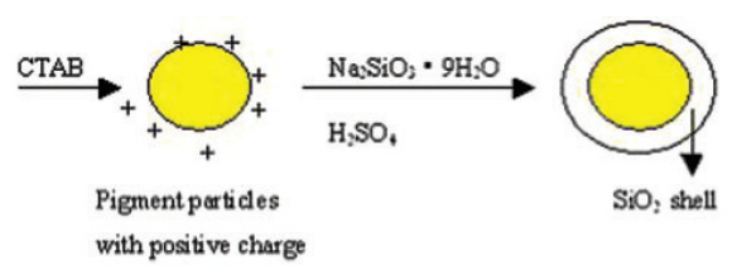

Figure 7. Mechanism of composite electrophoresis particle formation [83].

\subsection{Titanium}

Green pigments made with titanium dioxide or titania $\left(\mathrm{TiO}_{2}\right)$ are frequently used in the field of plastic production, building materials, glass coatings, and ceramics. Zou and Zhang [84] applied $\mathrm{TiO}_{2}$ as the core material to adjust the color properties of complex

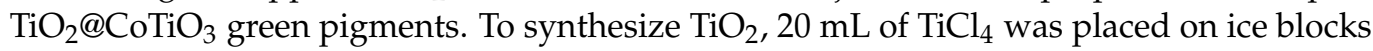
and stirred intensively. Once the blocks were fully melted, deionized water was added to dilute the solution to form $1 \mathrm{~mL}$ of precursor solution. Then, a dispersant $(1 \mathrm{wt} \%$ of PEG10000) was placed into the mixture, which was refluxed for $4 \mathrm{~h}$ at $100{ }^{\circ} \mathrm{C}$. About $10 \%$ of liquid ammonia was added to the solution to modify its $\mathrm{pH}$ value. The solution was washed multiple times and dried for $4 \mathrm{~h}$ at a temperature of $90{ }^{\circ} \mathrm{C}$ in order to collect the resultant $\mathrm{TiO}_{2}$ powder. Subsequently, as-prepared $\mathrm{TiO}_{2}$ powder was reinserted into the distilled water and stirred vigorously to produce $5 \mathrm{wt} \%$ of the suspension. After adding cobalt chloride to the mixture, $2 \mathrm{~mL}$ of sodium hydroxide solution was applied to increase the $\mathrm{pH}$ to 10 . This yielded the precipitate, which was filtered and washed multiple times. After drying at $105^{\circ} \mathrm{C}$ for $4 \mathrm{~h}$, the powder was calcined at different temperatures $\left(600-1000^{\circ} \mathrm{C}\right)$ for $60 \mathrm{~min}$, producing the final complex pigments.

\section{Core-Shell Synthesis Methods}

As aforementioned, core-shell particles are particles that consist of a shell and a core, wherein both can be made using the same or different materials $[45,85,86]$. Figure 8 shows various core/shell particles, wherein the core and shell are marked in different colors. The core can be in the form of a single sphere (Figure 8a) or a collection of many small spheres (Figure $8 b$ ). Moreover, there may be a hollow shell with a small sphere inside, which appears in a yolk-shell structure (Figure 8c) [87]. The shell structure may be in the form of a continuous layer (Figure 8a-c), multiple smaller spheres accumulated onto a larger core sphere (Figure 8d,e), or a simple collection of core spheres (Figure 8f) [88]. In fact, the insertion of smaller spheres into the shell can be performed to produce more intricate core/shell structures (Figure 8g) [89]. Alternatively, the same process can be carried out using multiple shells (Figure 8h) [90,91]. Varieties of chemical or physical methods can be used to synthesize core/shell nanoparticles, including wet chemistry and chemical/physical vapor deposition. Generally, multiple steps are involved in core-shell particle production. Typically, core particles are synthesized first; after which, a shell is created around the particle. However, the methods used to achieve these nanoparticles vary according to the type of core and shell materials under consideration [21]. The primary objective of core-shell particle preparation is to bring together the desired properties of 
diverse materials and structures to produce a synergistic effect, stabilize the active particles, and generate biocompatible properties [92]. Figure 8 illustrates various types of core-shell structures, depending on the type of core and shell materials, preparation method, and applications.

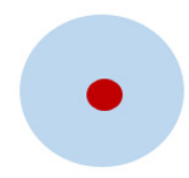

(a)

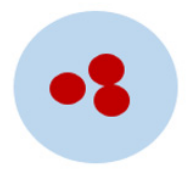

(b)

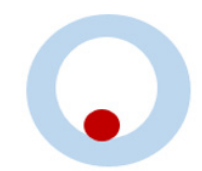

(c)

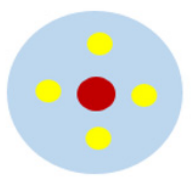

(g)

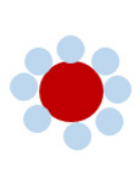

(d)

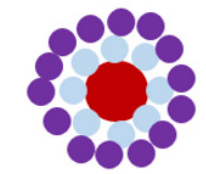

(e)

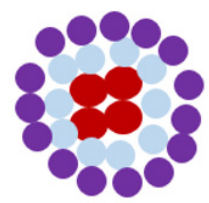

(f)

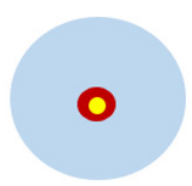

(h)

Figure 8. Schematic representation of different types of core-shell particles (a) single sphere (b) several small spheres (c) yolk-shell (d) small spheres onto small cores (e) small spheres onto big core (f) core spheres (g) smaller spheres into the shell (h) multiple shells.

Core-shell nanoparticles have become a fundamental nanomaterial for various industrial usages. During the preparation of core-shell NPs, it is important to identify a simple, quick, and cost-efficient method with the least-possible negative impacts on the environment. To meet this target, several methods have been developed, including the microemulsion, sol-gel, microwave synthesis, multistep reduction, epitaxial growth, electrochemical dealloying, sonochemical processing, and Stöber methods. Alternatively, these methods can be combined to create a hybrid method. Amongst all these approaches, the sol-gel method is most common for core-shell NP preparation. This method is a relatively new approach for preparing nanoparticles that allows for more control over the reaction processes involved in synthesizing solid materials. Homogenous multicomponent systems are easy to acquire, especially homogenous mixed oxides that can be prepared through the mixing of molecular precursor solutions. The sol-gel method is used in materials science to transform small molecules into solid materials. It is often applied to produce metal oxides like $\mathrm{SiO}_{2}$ and $\mathrm{TiO}_{2}$. To achieve this, the monomer must be converted into a colloidal solution (sol), which then serves as a precursor for a combined network consisting of network polymers or discrete particles. Generally, the metal alkoxides are used as precursors. During the chemical reaction, a colloidal solution called a "sol" is produced and gradually forms a gel-like diphasic substance consisting of a liquid and a solid phase. The morphologies of these phases can be in the form of discrete particles or continuous polymer networks. With regards to the colloid, it may be necessary to remove vast amounts of liquid if the volume fraction of the particles (or particle density) is extremely low in order to evoke the gel-like properties. It can be achieved in several ways, wherein the easiest one is to allow sufficient time for the sedimentation to occur. Subsequently, the remaining fluid can be poured away. Conversely, phase separation can be sped up through a process called centrifugation. As a wet chemical process, the sol-gel method is widely applied to produce core-shell nanoparticles [93-95].

Microemulsions are isotropic liquid mixtures consisting of water, surfactant, oil, and often, cosurfactants thermodynamically stable and clear in appearance. There may be salt present in the aqueous phase, as well as various other ingredients. The "oil" may actually be an intricate mix of various different hydrocarbons. As opposed to normal emulsions, microemulsions are created by mixing components, and no high shear conditions are required to produce them. There are three main types of microemulsions-namely, direct (oil dispersed in water, o/w), reversed (water dispersed in oil, w/o), and bi-continuous. 
Microemulsions are ternary systems in which two separate immiscible phases (water and "oil") occur with a surfactant, and the surfactant molecules can create a monolayer between the oil and water. Additionally, the surfactant molecules have hydrophobic tails that dissolve during the oil phase, whilst hydrophilic head groups dissolve in the liquid phase. To synthesize gold and silver core-shell bimetallic nanoparticles quickly, two-step microwave irradiation is often used. This strategy requires the creation of a bilayer organic barrier around the core, which is achieved using citrate and ascorbic acids, which serve as capping agents. In turn, this enables a well-defined boundary layer to be established between the core and the shell materials. The boundary layer plays a vital role in the process of synthesizing various core-shell particles, which results in the production of modifiable bimetallic NPs with clearly defined core/shell structures. These nanoparticles may have spherical or triangular seed cores.

Another technique that can be used to create core-shell materials such as carbon nanotubes is high-pressure chemical vapor deposition. This method was developed by Nikolaev et al. [96] with the main focus of creating a single-wall carbon nanotube by combing $\mathrm{CO}$ with a small quantity of $\mathrm{Fe}(\mathrm{CO})_{5}$ and passing the mixture through a heated reactor. El-Gendy et al. [97] synthesized carbon-coated Fe, Co, Ni, FeRu, CoRu, NiRu, NiPt, and CoPt nanoparticles using high-pressure chemical vapor deposition and manipulating the temperature and pressure inside the reactor. In these experiments, metal-organic precursors known as metallocenes (carbon-rich metal elements) were used. The precursors were inserted into a thermostatic sublimation chamber; after which, argon gas was passed through the chamber to push the vapor into the reactor's hot zone. The precursors could then break down the nanoparticles in the cooling finger. The precursor entered the gas phase in the hot zone to perform a supersaturation. Subsequently, the nanoparticles were nucleated when the supersaturation was achieved. The extent of a supersaturation can be changed by controlling the temperature inside the sublimation chambers and the pressure/temperature inside the chemical vapor deposition reactor. High pressure increases collisions between gas atoms, which ultimately reduces the rate at which atoms diffuse away from the original location. However, it is important to note that supersaturation cannot be achieved if the diffusion rate is poor, and this will result in single atoms or tiny clusters of atoms being deposited on the cooling finger.

The wet chemical technique was used [98] to synthesize $\mathrm{Fe}_{2} \mathrm{O}_{3}$ coated with graphene shells. A solution containing oleic acid and 1-octadecene was heated to $320{ }^{\circ} \mathrm{C}$ in a reflux reactor to dissolve purified iron oleate. Subsequently, ethanol and acetone were applied to wash the solution in order to generate iron oxide particles. Additionally, the Stöber process is commonly used to prepare silica $\left(\mathrm{SiO}_{2}\right)$ particles [99] of controllable and uniform size [100], and these particles can be used for many purposes in the field of material science. This method was proposed by Werner Stöber et al. in 1968 [99] and is still the most common wet chemistry synthetic approach employed to prepare silica nanoparticles [101]. This technique is a sol-gel process, in which a molecular precursor (typically tetraethylorthosilicate) is placed in water and reacted with an alcoholic solution. This causes the newly produced molecules to join together and create bigger structures.

$\mathrm{Du}$ et al. [102] used a sol-gel reaction to coat $\mathrm{Fe}_{3} \mathrm{O}_{4}$ nanoparticles with a $\mathrm{SiO}_{2}$ shell, yielding a core/shell structure. To synthesize the core/shell nanocomposites, a two-step procedure was used. First, the coprecipitation method was used to acquire $\mathrm{Fe}_{3} \mathrm{O}_{4}$ nanoparticles; after which, electrostatic interactions with tetramethylammonium hydroxide (TMAOH) were performed to disperse the particles in a liquid solution. Secondly, the produced $\mathrm{SiO}_{2}$ during the hydrolyzation of tetraethyl orthosilicate (TEOS) was used to cap $\mathrm{Fe}_{3} \mathrm{O}_{4}$. Figure 9 presents the sol-gel technique used by $\mathrm{Li}$ et al. [103] to produce $\mathrm{ZnSiO}_{3} / \mathrm{ZnO}$ core-shell nanoparticles. In this experiment, they combined the sol-gel with an annealing technique to synthesize zinc silicate-zinc oxide $\left(\mathrm{Zn}_{2} \mathrm{SiO}_{4} @ \mathrm{ZnO}\right)$ core-shell nanoparticles with a high band gap energy. First, the concentrations of the $\mathrm{Na}_{2} \mathrm{SiO}_{3} / \mathrm{ZnCl}_{2}$ precursors were modified to coat $\mathrm{ZnO}$ nanoparticles with $\mathrm{ZnSiO}_{3}$ shells of various thicknesses; after which, a low annealing temperature $\left(780^{\circ} \mathrm{C}\right)$ was set. This 
caused the amorphous $\mathrm{ZnSiO}_{3}$ to react with $\mathrm{ZnO}$ and to produce a crystalline $\mathrm{Zn}_{2} \mathrm{SiO}_{4}$ shell. The sol-gel technique was also used by Chai et al. [93] to produce core/shell-structured $\mathrm{Fe}_{3} \mathrm{O}_{4} @ \mathrm{SiO}_{2}$ nanoparticles. They employed a two-step process to create silica-coated magnetite $\left(\mathrm{Fe}_{3} \mathrm{O}_{4} @ \mathrm{SiO}_{2}\right)$ core-shell nanoparticles. Firstly, they used a solvothermal technique to fabricate $\mathrm{Fe}_{3} \mathrm{O}_{4}$ nanoparticles. Subsequently, $\mathrm{SiO}_{2}$ produced during the hydrolyzation of tetraethyl orthosilicate was used to coat the $\mathrm{Fe}_{3} \mathrm{O}_{4}$ nanoparticles.

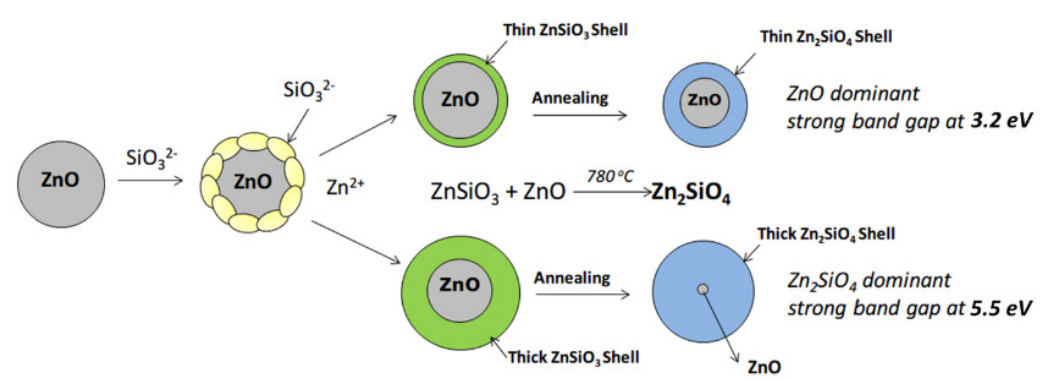

Figure 9. Sol-gel method for the fabrication of core-shell particles [103].

A two-step reduction method was used [104] to produce epitaxial Au@Ni core/shell nanocrystals. The first step involved mixing octahedral, triangular and hexagonal platelike, decahedral, and icosahedral crystals; after which, $\mathrm{HAuCl}_{4}$. was reduced in ethylene glycol (EG) and heated in a microwave with polyvinylpyrrolidone (PVP) added as a polymer surfactant. This enabled the core seeds to be produced. After this, oil bath heating was carried out to reduce $\mathrm{Ni}\left(\mathrm{NO}_{3}\right)_{2} \cdot 6 \mathrm{H}_{2} \mathrm{O}$ in $\mathrm{EG}$ with $\mathrm{NaOH}$ and PVP using oil bath heating in order to overgrow the Ni shells on the Au core seeds. Similarly, Fan et al. [105] employed a two-step seed-mediated growth technique using Au cores to test the synthesis of bimetallic core-shell nanocubes in liquid phases. The formation of heterogeneous core/shell structures for four typical noble metals (i.e., $\mathrm{Au}, \mathrm{Ag}, \mathrm{Pd}$, and $\mathrm{Pt}$ ) was systematically assessed. The findings of these experiments highlighted the growth modes and general requirements for achieving conformal epitaxial growth, as well as the heterogeneous nucleation and formation of different noble metals. It identified two types of growth for heterogeneous metal shells on gold cores-namely, conformal epitaxial growth (Au@Pd and Au@Ag nanocubes) and heterogeneous nucleation and island growth (Au@Pt nanospheres). Based on their findings, it was concluded that the two metals should have comparable lattice constants, with mismatches being below 5\%. Other researchers also confirmed the validity of these findings (Au@Ag (lattice mismatch, 0.2\%), Au@Pd (4.7\%), and Pt@Pd (0.85\%)) [106-108].

Tsuji et al. [109] used a one-pot polyol technique to synthesize Ag@Cu core-shell nanoparticles with a high yield. In this method, bubbling Ar gas was used. Chemical reagents such as $\mathrm{AgNO}_{3}$ and $\mathrm{Cu}(\mathrm{OAc})_{2} \cdot \mathrm{H}_{2} \mathrm{O}$ were added to serve as the reagents. First, $\mathrm{AgNO}_{3}$ was reduced in ethylene glycol (EG) to synthesize Ag@Cu particles via a two-step process. To start, Ag cores particles were separated from $\mathrm{AgNO}_{3}$; after which, $\mathrm{Cu}(\mathrm{OAc})_{2} \cdot \mathrm{H}_{2} \mathrm{O}$ was added to create $\mathrm{Cu}$ shells. However, this was ineffective and produced no $\mathrm{Cu} @ \mathrm{Ag}$ core-shell particles; rather, $\mathrm{Cu} / \mathrm{Ag}$ bi-compartmentalized particles were produced. In this work, Ag@Cu particles were prepared using different methods at various reaction temperatures and heating times. It was observed that adding the two reagents in reverse was the most effective way of producing $\mathrm{Ag} @ \mathrm{Cu}$ particles. To start the process, $8 \mathrm{~mL}$ of $15.9-\mathrm{mM} \mathrm{Cu}(\mathrm{OAc})_{2} \cdot \mathrm{H}_{2} \mathrm{O}$ in $\mathrm{EG}$ and $8 \mathrm{~mL}$ of $477-\mathrm{mM}$ poly(vinylpyrrolidone) (PVP; MW: 55,000 monomer units) were placed in EG, and the solution was mixed in a 100-mL three-necked flask. To eliminate all of the oxygen from the solution, Ar gas was bubbled for $10 \mathrm{~min}$ at room temperature. The solution was soaked in an oil bath at $180{ }^{\circ} \mathrm{C}$. Subsequently, the temperature was increased to $175^{\circ} \mathrm{C}$, and the solution was left to bubble in Ar for several minutes; after which, $2 \mathrm{~mL}$ of $15.7-\mathrm{mM} \mathrm{AgNO}_{3}$ was added to the reagent solution and kept for $20 \mathrm{~min}$ at $175^{\circ} \mathrm{C}$. The concentrations of the final yields were $7.0 \mathrm{mM}$ for $\mathrm{Cu}(\mathrm{OAc})_{2} \cdot \mathrm{H}_{2} \mathrm{O}, 1.7 \mathrm{mM}$ for $\mathrm{AgNO}_{3}$, and $212 \mathrm{mM}$ for PVP. The influence of different 
reaction times was tested on the reagent solution to further investigate the Ag@Cu growth process.

A modified Stöber technique was used by Chae et al. [93] to produce $\mathrm{Fe}_{3} \mathrm{O}_{4} @ \mathrm{SiO}_{2}$. A sol-gel method was employed to prepare the $\mathrm{Fe}_{3} \mathrm{O}_{4} @ \mathrm{SiO}_{2}$ nanoparticles. The synthesis method involved the addition of $4 \mathrm{~g}$ of $\mathrm{Fe}_{3} \mathrm{O}_{4}$ particles and $4 \mathrm{~mL}$ of tetraethyl orthosilicate to $40 \mathrm{~mL}$ of deionized water, followed by ultrasonication to mix the solution, forming a stable emulsion. Thereafter, the emulsion was inserted into a mixture containing $50 \mathrm{~mL}$ of ethanol and $12 \mathrm{~mL}$ of $\mathrm{NH}_{3} \cdot \mathrm{H}_{2} \mathrm{O}$. The resultant solution was stirred for $4 \mathrm{~h}$ at room temperature at a rate of $400 \mathrm{rpm}$, followed by centrifugation to separate the core-shell structure of $\mathrm{Fe}_{3} \mathrm{O}_{4} @ \mathrm{SiO}_{2}$. Figure 10 demonstrates the procedure for $\mathrm{Fe}_{3} \mathrm{O}_{4} @ \mathrm{SiO}_{2}$ synthesis.
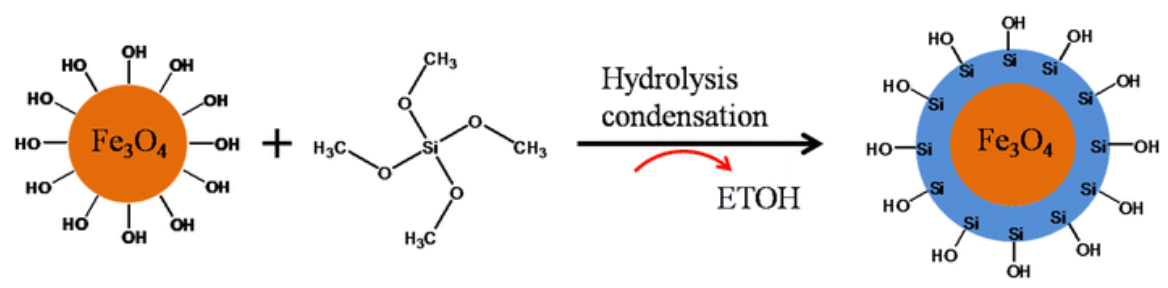

Figure 10. The Stöber method for $\mathrm{Fe}_{3} \mathrm{O}_{4} @ \mathrm{SiO}_{2}$ nanoparticle synthesis [93].

Sharma et al. [110] showed that core/shell particles can be fabricated through precipitation without a surfactant. They investigated the impacts of different surfactants and various concentrations on core-shell particle development. To investigate this, anionic and nonionic surfactants were tested. Additionally, fly ash was employed to create nanoTiO 2 for shell coating [110]. The main purpose of using surfactants was to enhance nanotitania shells' adhesion to fly ash core. It was concluded that, to determine the optimum impacts of $\mathrm{TiO}_{2}$ adhesion onto fly ash, various surfactants must be tested. One test was carried out without a surfactant, whilst other tests employed anionic and nonionic surfactants. The particles produced with the addition of an anionic surfactant were found to have better pigment properties and reflectance in the near-infrared area than the one obtained without a surfactant. Thus, such systems were claimed to be used effectively as a pigment in cool coatings. Fly ash was placed in a solution containing $70 \%$ ethanol supplemented with an anionic (SDS) or nonionic surfactant (TX-100). Next, titanium isopropoxide was added to the solution, followed by stirring for two hours. After two hours, the solution was dried in the range of $50-600{ }^{\circ} \mathrm{C}$, and the resultant dry powder was collected. An experiment was conducted [111] using the semi-batch emulsion polymerization method to synthesize PUA hybrid emulsion PA/PU with a ratio of 20/80. A 250-mL four-neck glass flask containing a reflux condenser, digital thermometer, nitrogen gas inlet, and mechanical stirrer was used in this synthesis process. To prepare the pre-emulsion, SDS (2.0 g per $100 \mathrm{~g}$ of the acrylic and PU content) was dissolved in water. Subsequently, 5.0 g of MMA, $5.0 \mathrm{~g}$ of BA, and $0.015 \mathrm{~g}$ of AA $(0.15 \mathrm{wt} \%$ of the overall MMA and BA weights) were added gradually to the emulsifier mixture and constantly stirred. The emulsion was then mixed for another $0.5 \mathrm{~h}$. First, the reactor vessel was charged to achieve 111.3-g PU emulsion dispersion and $10 \%$ of the monomers. Then, it was set at $80{ }^{\circ} \mathrm{C}$ with constant stirring. Later, $10 \%$ of the initiator solution ( $0.4 \mathrm{~g}$ of KPS per $100 \mathrm{-g}$ acrylic monomers) was added to the solution and stirred for half an hour. Then, at a constant flow rate, the leftover monomer pre-emulsion and initiator solution was poured into the flask for a total of $4 \mathrm{~h}$ while the temperature was increased by $5^{\circ} \mathrm{C}$, keeping the solution at $85^{\circ} \mathrm{C}$ for half an hour. The emulsion was then stirred continuously while left to cool. After adding $\mathrm{NaHCO}_{3}$, the $\mathrm{pH}$ value was kept within the predetermined range.

In brief, all the developed methods to date have aimed for the green and effective synthesis of core-shell NPs with controllable sizes, compositions, architectures, and properties through rational molecular design and material preparations. Despite substantial advances in the methods of preparation of core-shell nanostructures, the one-step/pot strategy in the preparation of core-shell nanostructures is still in its infancy and remains 
challenging. For example, the facet control of metal@metal oxide crystalline nanoparticles in a one-step co-reduction is limited compared to those prepared through a two-step seed-coating process.

\section{Efficiency and Test Methods}

\subsection{Structure and Morphology}

Various characterization tools can be used to evaluate the properties of synthesized core-shell nanoparticles. These techniques include XRD, SEM, TEM, FTIR, BET, LC-MS, XPS, Raman spectroscopy, ultraviolet-visible-NIR absorption spectroscopy, NIR reflectance, and photoluminescence spectroscopy $[45,61,63,70,84,86,95,112-116]$. For example, XRD, SEM, TEM, FTIR, and XPS tests were carried out [28] to assess the structure, morphology, and chromaticity of $\alpha-\mathrm{Fe}_{2} \mathrm{O}_{3} @ \mathrm{SiO}_{2}$ fabricated pigments. Figure 11a presents the XRD patterns of the reddish pigments $\alpha-\mathrm{Fe}_{2} \mathrm{O}_{3}, \alpha-\mathrm{Fe}_{2} \mathrm{O}_{3} @ \mathrm{SiO}_{2} \mathrm{NPs}$, and $\alpha-\mathrm{Fe}_{2} \mathrm{O}_{3} @ \mathrm{SiO}_{2}$. The diffraction peak of $\alpha-\mathrm{Fe}_{2} \mathrm{O}_{3} @ \mathrm{SiO}_{2}$ particles were wide $\left(2 \theta=15-25^{\circ}\right)$ once the core-shell structures formed, suggesting that there may be amorphous $\mathrm{SiO}_{2}$ present. Moreover, the diffraction peak changed to approximately $22^{\circ}$ after calcination at $1000^{\circ} \mathrm{C}$, which suggested that the amorphous silica shell entered into the cristobalite phase to produce a reddish pigment. In addition, the $\alpha-\mathrm{Fe}_{2} \mathrm{O}_{3}$ diffraction peak became weaker once the core-shell structure was formed. Figure $11 \mathrm{~b}$ displays the FTIR results for $\alpha-\mathrm{Fe}_{2} \mathrm{O}_{3}, \alpha-\mathrm{Fe}_{2} \mathrm{O}_{3} @ \mathrm{SiO}_{2} \mathrm{NPs}$, and $\alpha-\mathrm{Fe}_{2} \mathrm{O}_{3} @ \mathrm{SiO}_{2}$ reddish pigments. The bands at 3423.50 and $1627.85 \mathrm{~cm}^{-1}$ corresponded to the stretching of hydroxyl $(-\mathrm{OH})$, and the bands at 536.19 and $466.75 \mathrm{~cm}^{-1}$ were due to the $\mathrm{O}-\mathrm{Fe}-\mathrm{O}$ bond vibration of $\alpha-\mathrm{Fe}_{2} \mathrm{O}_{3}$. After covering $\alpha-\mathrm{Fe}_{2} \mathrm{O}_{3}$ in $\mathrm{SiO}_{2}$, bands were developed at 1091.66 and $470 \mathrm{~cm}^{-1}$. The bands were due to the bending and stretching of $\mathrm{O}-\mathrm{Si}-\mathrm{O}$, indicating that a coating was created on the $\alpha-\mathrm{Fe}_{2} \mathrm{O}_{3}$ surface. Furthermore, the intensity of the $\mathrm{O}-\mathrm{Si}-\mathrm{O}$ band became stronger once it was calcined, improving the interaction between the core and shell materials. XPS was used to further assess the reddish pigments, and the results are presented in Figure 11c,d. The high-resolution XPS spectrum showed intense $\mathrm{O}$ 1s peaks, verifying the presence of $\mathrm{Fe}-\mathrm{O}$ bonds and $\mathrm{Si}-\mathrm{O}$ bonds in the pigment (Figure 11c). Meanwhile, a band was observed at $103.5 \mathrm{eV}$ corresponding to the $\mathrm{Si}$ $2 p$ XPS signal, which is commonly seen in pure silica.
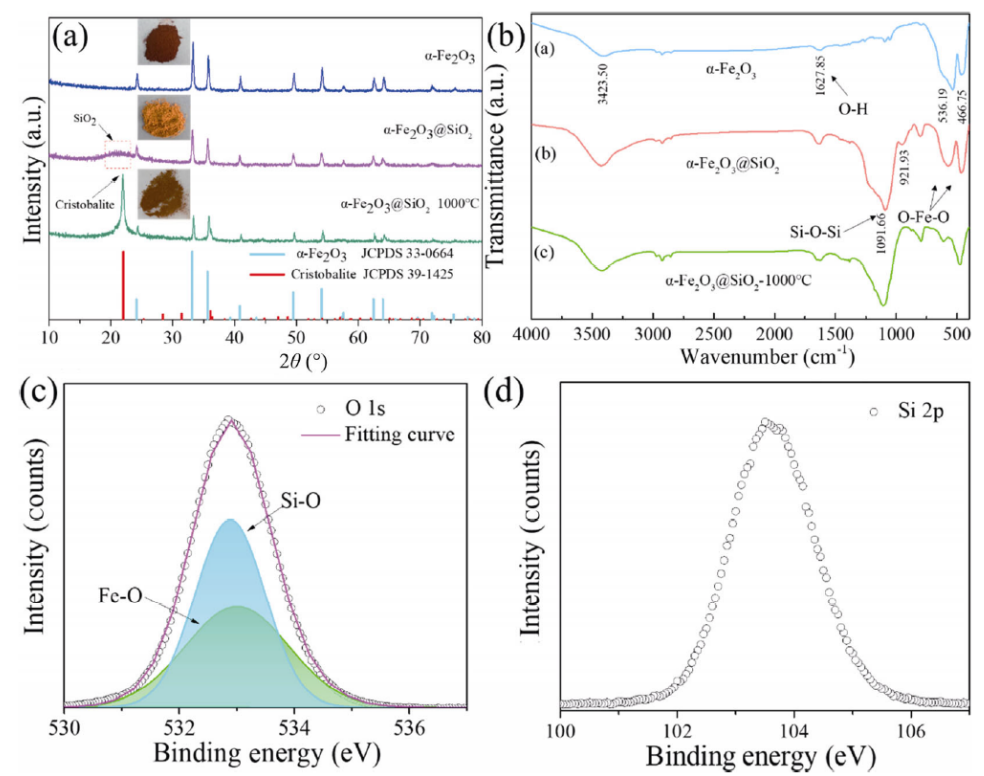

Figure 11. (a) XRD patterns and (b) FTIR spectra of different samples; high-resolution XPS spectra of (c) $\mathrm{O} 1 \mathrm{~s}$ and (d) $\mathrm{Si} 2 \mathrm{p}$ for $\alpha-\mathrm{Fe}_{2} \mathrm{O}_{3} @ \mathrm{SiO}_{2}$ pigments calcined at $1000{ }^{\circ} \mathrm{C}$ [28].

Li et al. [95] recorded the TEM images of synthesized $\gamma-\mathrm{Ce}_{2} \mathrm{~S}_{3} @ \mathrm{SiO}_{2}$ core-shell materials. Figure 12 shows the formation of the silica shell with different coating times. $\gamma-\mathrm{Ce}_{2} \mathrm{~S}_{3}$ was covered in a clear layer that was not present on the uncoated samples, thereby support- 
ing the findings of the SEM analysis. Figure $12 b-d$ showed that, with the increase of the coating times, the thickness of the coating layer also increased. For example, the coating layer thicknesses of the particles coated once, twice, and three times were $70 \mathrm{~nm}, 100 \mathrm{~nm}$ and $140 \mathrm{~nm}$, respectively. These disclosures indicated that, by varying the coating times, the thickness of the coating layers can be modified.
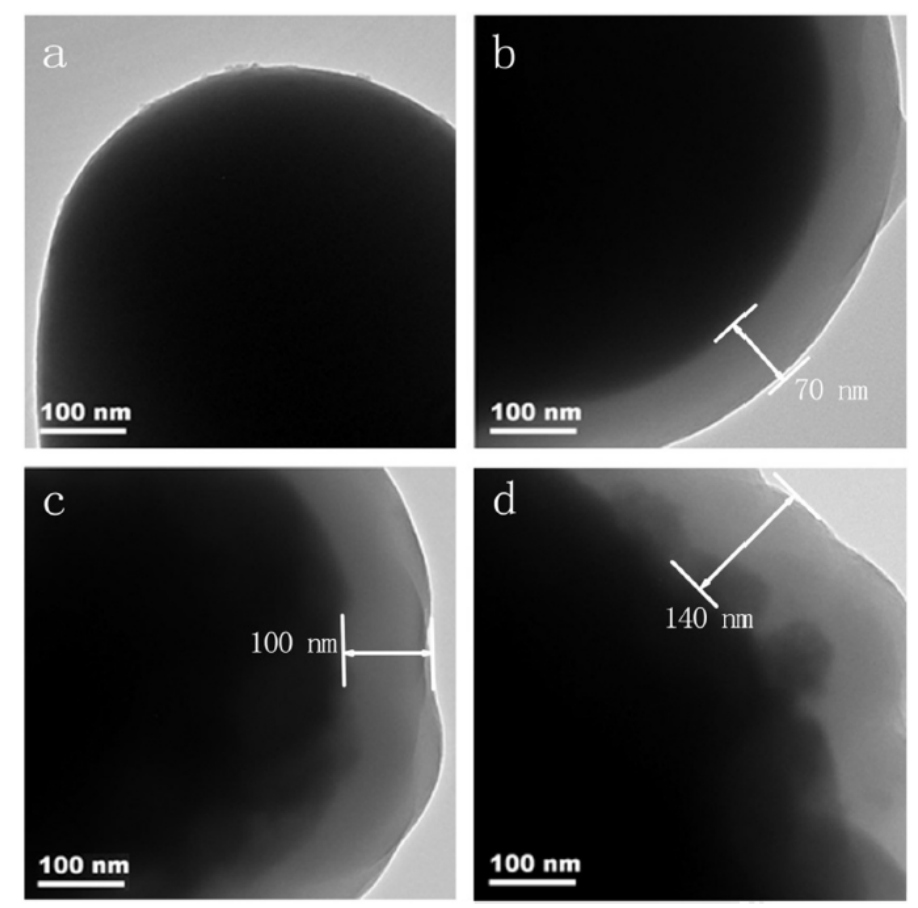

Figure 12. TEM images of (a) uncoated $\gamma-\mathrm{Ce}_{2} \mathrm{~S}_{3}$ and (b) once, (c) twice, and (d) three times-coated $\gamma-\mathrm{Ce}_{2} \mathrm{~S}_{3} @ \mathrm{SiO}_{2}$ core-shell particles [95].

Liu et al. [62] fabricated $\gamma-\mathrm{Ce}_{2} \mathrm{~S}_{3} @ \mathrm{SiO}_{2}$ materials and characterized them using the TEM, FTIR, EDS, and XRD tests to determine their structures and morphologies. First, the TEM image analyses were performed to measure the thickness of $\mathrm{SiO}_{2}$-coated $\gamma-\mathrm{Ce}_{2} \mathrm{~S}_{3}$. Figure 13 shows the TEM micrographs of the uncoated $\gamma-\mathrm{Ce}_{2} \mathrm{~S}_{3}$ pigments and $\mathrm{SiO}_{2}$ xerogelcoated $\gamma-\mathrm{Ce}_{2} \mathrm{~S}_{3}$ prepared with different water-to-ethanol volume ratios. Figure 13a shows that uncoated $\gamma-\mathrm{Ce}_{2} \mathrm{~S}_{3}$ pigments take the form of irregularly shaped large chunks, with small particles deposited at the surface. The EDS spectra detected the presence of $\mathrm{Zn}$, meaning that the uncoated $\gamma-\mathrm{Ce}_{2} \mathrm{~S}_{3}$ pigments were changed via $\mathrm{ZnO}$, enhancing the color stability and lowering the $\mathrm{H}_{2} \mathrm{~S}$ emissions of the pigments. Figure $13 \mathrm{~b}-\mathrm{d}$ displays all the pigment particles with core-shell structures following the coating process. The EDS spectra (Figure 13f) revealed the presence of $\mathrm{Si}$ in the structure. These findings evidently suggested that the coating layer deposited on the surface of $\gamma-\mathrm{Ce}_{2} \mathrm{~S}_{3}$ was $\mathrm{SiO}_{2}$ xerogel. Figure $13 \mathrm{~b}, \mathrm{c}$ revealed a relatively uniform shell size when the water-to-ethanol volume ratios of 15:105 $(48 \mathrm{~nm})$ and 20:100 $(60 \mathrm{~nm})$ were employed. Conversely, the shell thickness seemed to be nonuniform when this ratio was changed to 25:95 (Figure 13d). This was mainly due to the speeding up of TEOS hydrolysis when the water volume was increased. It seems that the silica nuclei and surface nuclei began competing with each other during the coating process, thus resulting in nonuniform shell thicknesses. 

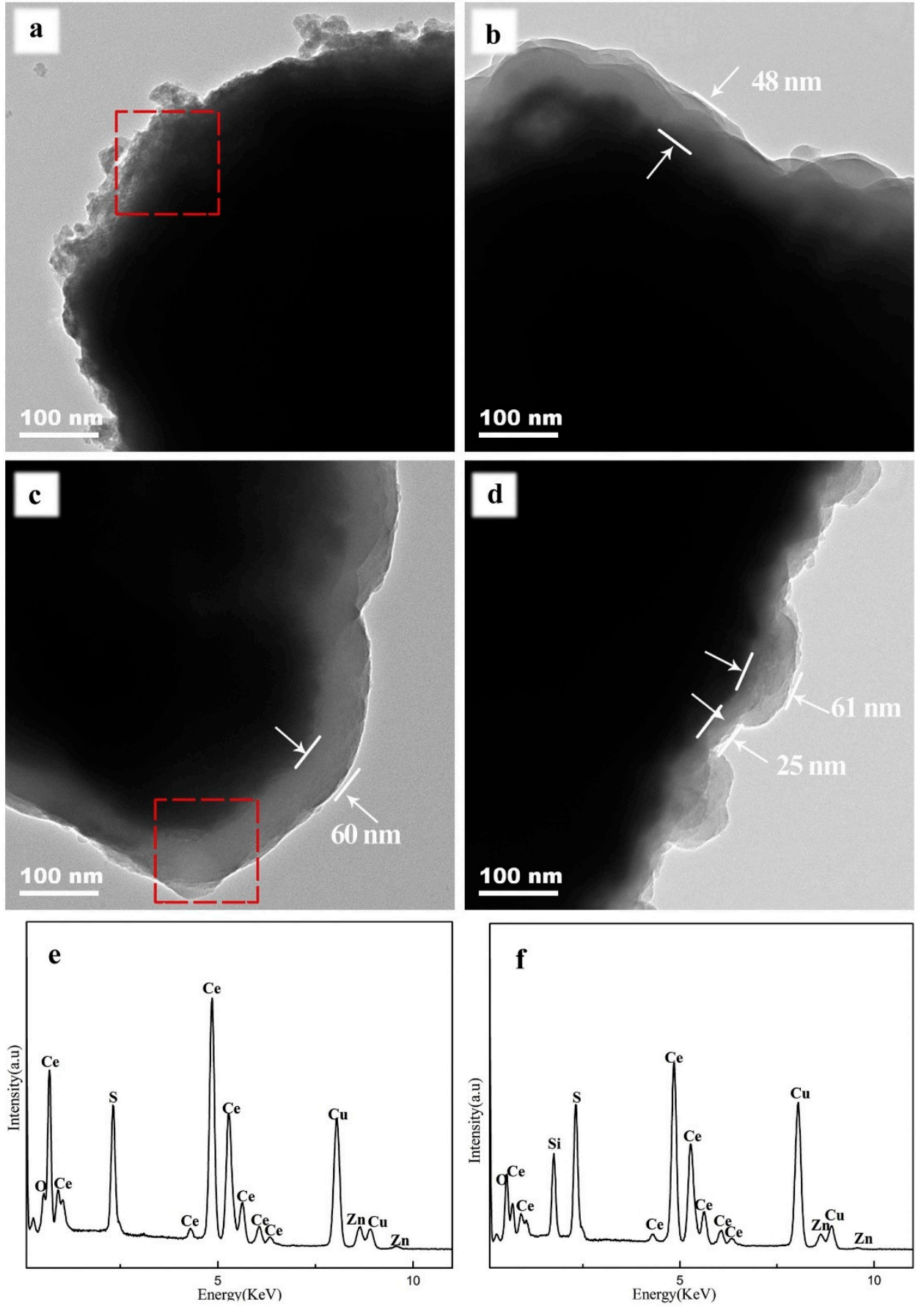

Figure 13. TEM images and EDS patterns of $\mathrm{SiO}_{2}$ xerogel-coated $\mathrm{Ce}_{2} \mathrm{~S}_{3}$ prepared with different water-to-ethanol ratios. (a) S0, (b) S1, (c) S2, (d) S3, (e) EDS spectra of S0, and (f) EDS spectra of S2 [62].

\subsection{Reflectivity}

The results showed that the crystallization of $\mathrm{Fe}_{2} \mathrm{O}_{3}(\mathrm{CF})$ and $\mathrm{TiO}_{2}(\mathrm{CT})$ highly enhances NIR reflectance. Figure 14 shows the reflectance spectra of CT, CFT2, CFT4, CFT5, and the CF sample [65]. In the CT sample, the crystallinity was increased in the rutile phase, which ultimately enhanced the reflectivity at all wavelengths. Moreover, the crystallization of the sample seems to increase the reflectance values following the calcination process. The observed darker hues of the samples in Figure 14c were due to the $\mathrm{Fe}_{2} \mathrm{O}_{3}$ content, reducing the NIR reflectance. The NIR solar reflectance of samples CT, CFT2, CFT4, CFT5, and CF 
were $76 \%, 73 \%, 68.8 \%, 68.4 \%$, and $39.3 \%$, respectively. Figure $14 \mathrm{~d}$ shows the mechanism of IR reflectance in the $\mathrm{Fe}_{2} \mathrm{O}_{3}$ and $\mathrm{Fe}_{2} \mathrm{O}_{3}-\mathrm{TiO}_{2}$ particles.
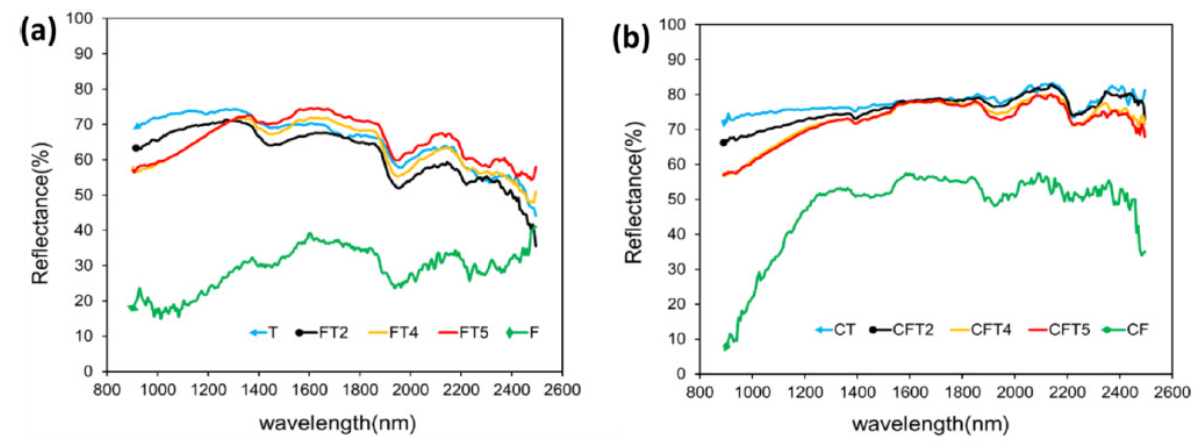

(c)

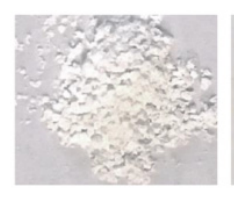

CT

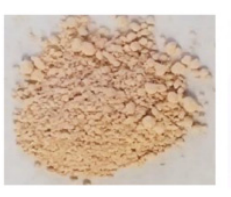

CFT
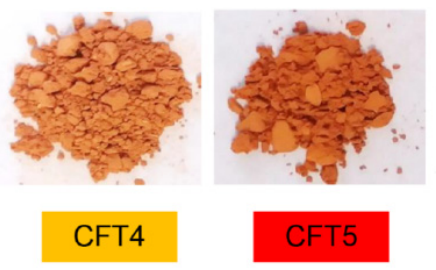

CFT5

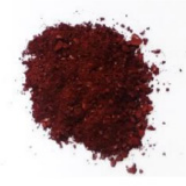

CF

(d)
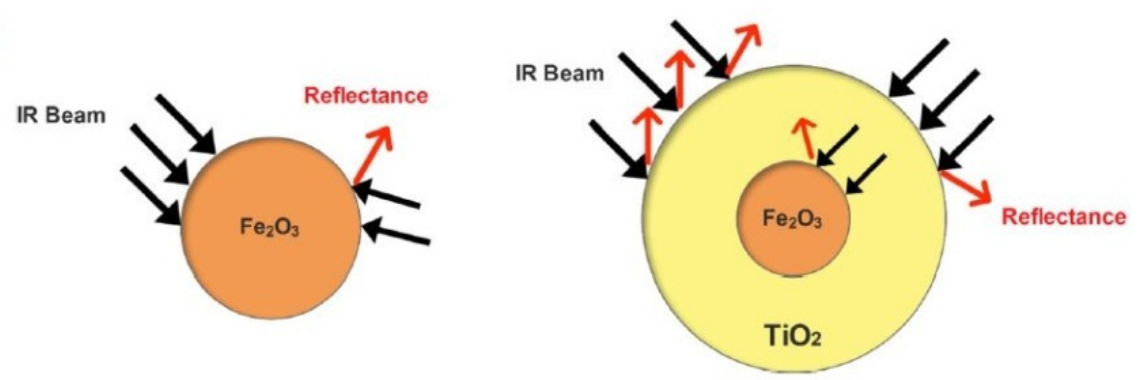

Figure 14. Reflectance spectra of the (a) fabrication of $\mathrm{TiO}_{2}(\mathrm{~T}), \mathrm{Fe}_{2} \mathrm{O}_{3} @ \mathrm{TiO}_{2}$ with 0.02 ratio of $\mathrm{Fe}_{2} \mathrm{O}_{3}$ to $\mathrm{TiO}_{2}$ (FT2), $\mathrm{Fe}_{2} \mathrm{O}_{3} @ \mathrm{TiO}_{2}$ with 0.62 ratio of $\mathrm{Fe}_{2} \mathrm{O}_{3}$ to $\mathrm{TiO}_{2}(\mathrm{FT} 4), \mathrm{Fe}_{2} \mathrm{O}_{3} @ \mathrm{TiO}_{2}$ with 1.24 ratio of $\mathrm{Fe}_{2} \mathrm{O}_{3}$ to $\mathrm{TiO}_{2}$ (FT5), and $\mathrm{Fe}_{2} \mathrm{O}_{3}$ (F) samples. (b) The crystallite of $\mathrm{TiO}_{2}$ (CT), $\mathrm{Fe}_{2} \mathrm{O}_{3} @ \mathrm{TiO}_{2}$ with size $31.4 \mathrm{~nm}$ (CFT2), $\mathrm{Fe}_{2} \mathrm{O}_{3} @ \mathrm{TiO}_{2}$ with size $28.4 \mathrm{~nm}(\mathrm{CFT} 4), \mathrm{Fe}_{2} \mathrm{O}_{3} @ \mathrm{TiO}_{2}$ with size $13.3 \mathrm{~nm}$ (CFT5), and $\mathrm{Fe}_{2} \mathrm{O}_{3}$ (CF) samples. (c) Photographs of the CT, CFT2, CFT4, CFT5, and CF samples. (d) The proposed mechanism of IR reflectance in $\mathrm{Fe}_{2} \mathrm{O}_{3}$ and the $\mathrm{Fe}_{2} \mathrm{O}_{3} @ \mathrm{TiO}_{2}$ composites [65].

\subsection{Toleration of High Temperatures}

The effects of $\mathrm{Ce}_{2} \mathrm{~S}_{3} @ \mathrm{SiO}_{2}$-based core-shell materials on red pigment tolerance at high temperatures were assessed [57]. Figure 15 shows the XRD patterns of $\gamma-\mathrm{Ce}_{2} \mathrm{~S}_{3} @ \mathrm{C}-\mathrm{SiO}_{2}$ samples produced at different calcination temperatures. No typical $\mathrm{SiO}_{2}$ diffraction peaks were identified at calcination temperatures between 1100 and $1150^{\circ} \mathrm{C}$. In addition, the diffraction peaks were evidenced in the $\gamma-\mathrm{Ce}_{2} \mathrm{~S}_{3}$ crystalline phase, suggesting that $\mathrm{SiO}_{2}$ did not crystallize. Nonetheless, when the temperature was increased to $1200{ }^{\circ} \mathrm{C}$, the typical c-SiO ${ }_{2}$ diffraction peak started to emerge, indicating that $\mathrm{SiO}_{2}$ started to crystallize at $1200{ }^{\circ} \mathrm{C}$ in the $\mathrm{Ar}$ gas atmosphere. The intensity of the c- $\mathrm{SiO}_{2}$ diffraction peak was almost constant when the temperature was increased to $1250{ }^{\circ} \mathrm{C}$. At $1200{ }^{\circ} \mathrm{C}$ and in an Ar gas atmosphere, $\mathrm{c}_{-} \mathrm{SiO}_{2}$ seemed to develop excellent crystallinity. Li et al. [113] carried out an XRD test to analyze the thermal resistance of $\gamma-\mathrm{Ce}_{2} \mathrm{~S}_{3}$ red pigments. 


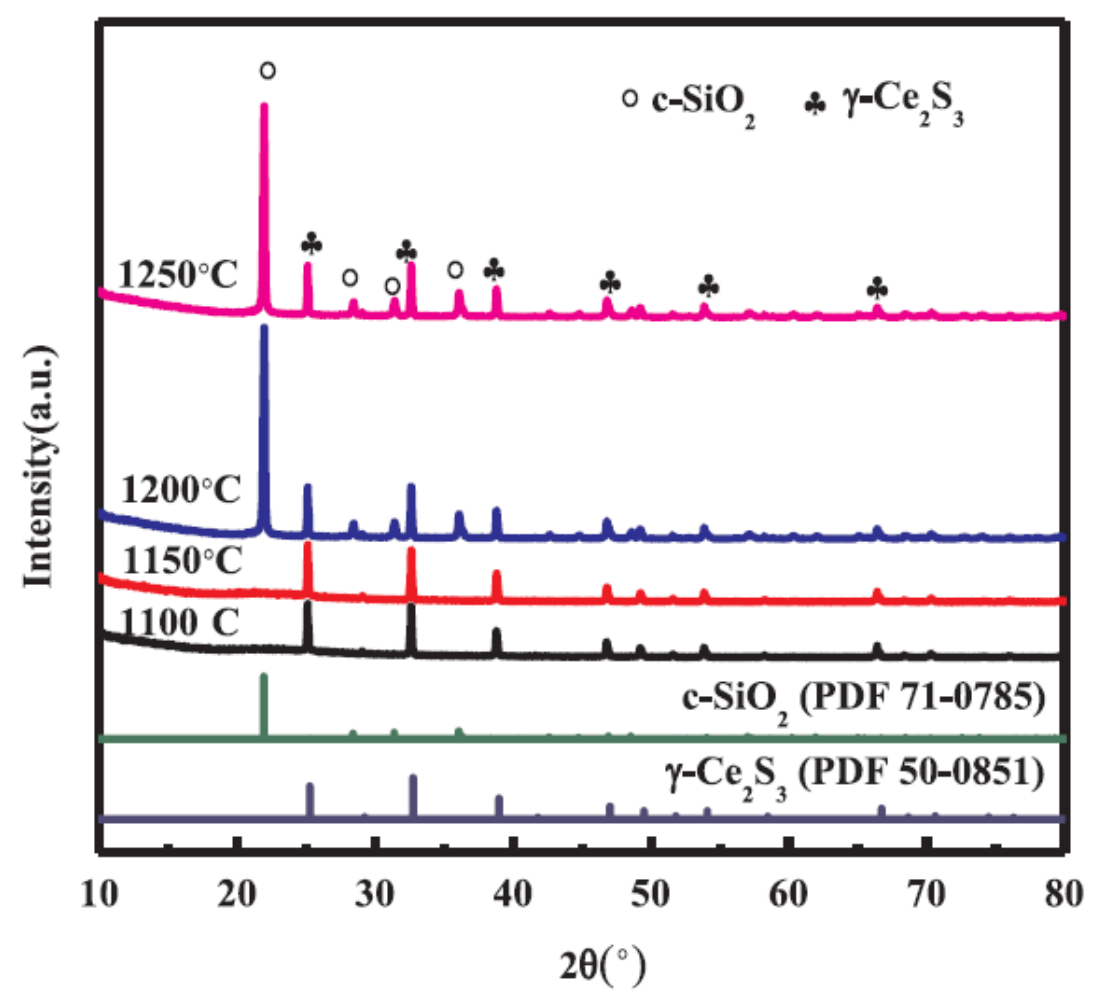

Figure 15. XRD patterns of the $\gamma-\mathrm{Ce}_{2} \mathrm{~S}_{3} @_{\mathrm{c}}-\mathrm{SiO}_{2}$ samples at different sintering temperatures in an Air gas atmosphere [57].

The effect of the $\mathrm{Fe}_{2} \mathrm{O}_{3}$-to- $\mathrm{TiO}_{2}$ ratio and calcination temperatures on the color stability of $\mathrm{Fe}_{2} \mathrm{O}_{3} @ \mathrm{TiO}_{2}$-modified red pigments was evaluated [116]. With an increase of the $\mathrm{Fe}_{2} \mathrm{O}_{3}$ content with $\mathrm{Fe}_{2} \mathrm{O}_{3}$-to-TiO ${ }_{2}$ ratios of 0.5 (FT-1), 1.0 (FT-2), and 1.5 (FT-3) at the same heat treatment temperature, the color of the $\mathrm{Fe}_{2} \mathrm{O}_{3} @ \mathrm{TiO}_{2}$ powder approached the color of pure $\mathrm{Fe}_{2} \mathrm{O}_{3}$. When observed with the naked eye at a fixed $\mathrm{Fe}_{2} \mathrm{O}_{3} @ \mathrm{TiO}_{2}$ ratio, the color of the pigment did not change significantly as the heat treatment temperatures were increased from $500{ }^{\circ} \mathrm{C}$ to $700{ }^{\circ} \mathrm{C}$. However, at $800{ }^{\circ} \mathrm{C}$, the FT-2 and FT-3 powder colors showed darker reds than the ones calcined at low temperatures, wherein FT- 1 and pure $\mathrm{Fe}_{2} \mathrm{O}_{3}$ changed completely to different colors (Figure 16). It was concluded that, to get a red color $\mathrm{Fe}_{2} \mathrm{O}_{3} / \mathrm{TiO}_{2}$ pigment powder like pure $\mathrm{Fe}_{2} \mathrm{O}_{3}$, the weight ratio of $\mathrm{Fe}_{2} \mathrm{O}_{3}$ to $\mathrm{TiO}_{2}$ should be 1.0 or higher, and the post-heat treatment temperature should be $700{ }^{\circ} \mathrm{C}$ or lower. The XRD test was used to explain the effect of the $\mathrm{Fe}_{2} \mathrm{O}_{3}$-to- $\mathrm{TiO}_{2}$ ratio on the improved color stability of the core@shell composite. For pure $\mathrm{Fe}_{2} \mathrm{O}_{3}$, the crystallite size was increased linearly with the rise of the calcination temperature. The increase in the $\mathrm{Fe}_{2} \mathrm{O}_{3}$ crystallite size in the $\mathrm{Fe}_{2} \mathrm{O}_{3} @ \mathrm{TiO}_{2}$ (FT-2) composite pigment was smaller than that of pure $\mathrm{Fe}_{2} \mathrm{O}_{3}$ due to the increase in the calcination temperature, and the crystallite size was decreased at $800{ }^{\circ} \mathrm{C}$. Concisely, the growth of the $\mathrm{Fe}_{2} \mathrm{O}_{3}$ crystals depended significantly on the heat treatment temperature when coated on the $\mathrm{TiO}_{2}$ surface, and the $\mathrm{Fe}_{2} \mathrm{O}_{3}$ crystals did not grow anymore at $800{ }^{\circ} \mathrm{C}$ or higher. 


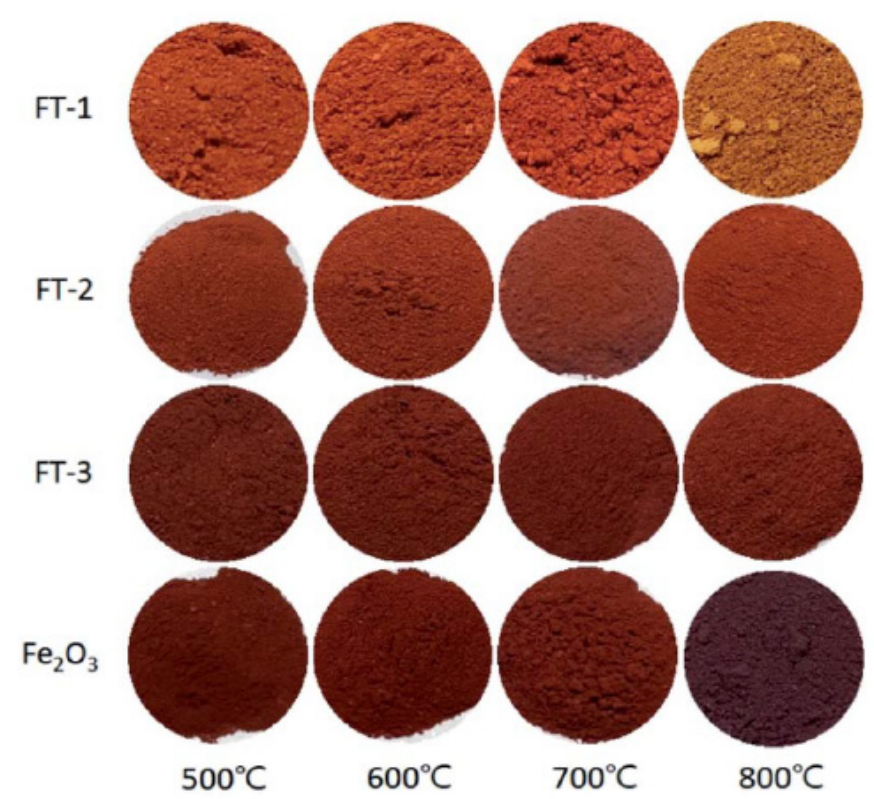

Figure 16. The effect of calcination temperature on the color stability of $\mathrm{Fe}_{2} \mathrm{O}_{3} @ \mathrm{TiO}_{2}$ [116].

\section{Applications of Core-Shell Pigments}

Core-shell pigments can be used to decorate or delineate features in public streets, which can ultimately enhance public safety and satisfaction. The development of good infrastructures and clear frameworks can encourage individuals to walk, cycle, and use Personal Mobility Devices (PMDs), which, in turn, lowers the number of short car journeys being made and, thus, promotes a healthier lifestyle. In Figure 17, the various uses of red pigments on pedestrian roads in Singapore are presented. Material failures remains a significant concern throughout the construction industry, despite the improved understanding of its causes and effects. High-performance coatings are typically applied to enhance exterior durability, whilst pigments are usually selected based on a combination of color and performance [114]. High-quality pigments are used almost exclusively in the paint industry, where optimal, uniform particle sizes are crucial, as they impact the gloss, hiding power, lightening capacity, and tinting strength of the paint. What is more, nanoscale pigment particles are required in applications such as coloring and UV coatings on luminescent materials.

Colored asphalt and red concrete are often preferred over conventional materials, since the latter has poor esthetic properties from an architectural design perspective [115]. Significant advancements have been made in nanotechnology and nanomaterials over the last few years, enabling the synthesis of core-shell nanoparticles to create sustainable pigments with high color stability and resistance to harsh environmental conditions. The emergence of new, durable pigments has increased the potential uses of colored concrete and asphalt by creating alternatives that can be used in challenging architectural designs that have high color stability and resistance to abrasions. These features combined with the existing aesthetic and decorative features of traditional colored concrete can create attractive alternative materials. 


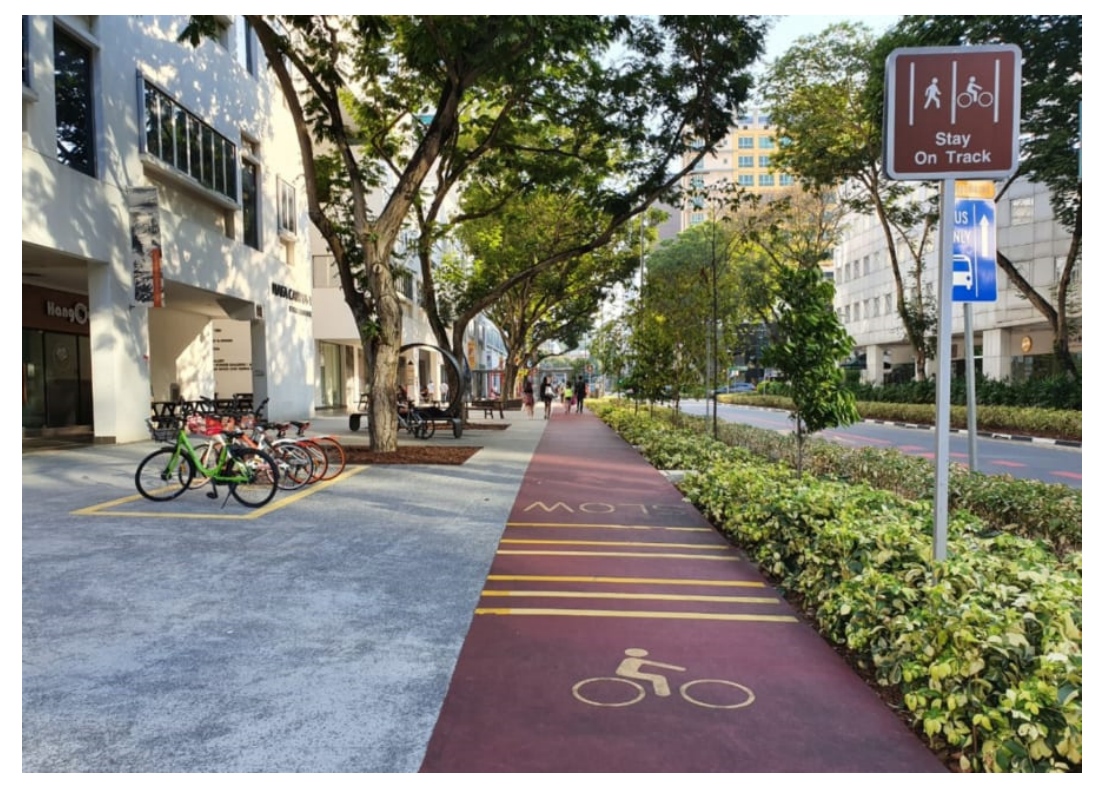

Figure 17. Red pigments applied on Singapore's cyclist and pedestrian roads.

\section{Conclusions}

In recent times, sustainable pigments produced via advanced nanotechnologies and core-shell technologies have become useful in construction industries worldwide. An allinclusive overview of the relevant literature on nanotechnology-based core-shell pigments allowed us to draw the following conclusions:

i. The ability to manipulate particle structures at the nanoscale has led to the emergence of a new class of engineered hybrid NPs and core-shell NPs.

ii. With the rapid development of synthetic chemistry and colloid and interfacial science, as well as devices, many core-shell nanostructures have been successfully fabricated using different strategies.

iii. All the fabrication processes aim for the green color core-shell NPs with controllable sizes, compositions, architectures, and properties through rational molecular design and appropriate materials (inexpensive and environmentally friendly).

iv. Using core-shell NPs, it is possible to enhance a pigment's durability, performance, and sustainability, which is demanded for several applications.

v. Owing to their efficiency and distinct traits, $\mathrm{SiO}_{2}$ and $\mathrm{TiO}_{2}$ are the most-recommended materials for shell formation in core-shell nanostructures.

vi. The TEM, SEM, EDX, FTIR, and XRD tests can reliably be used to measure and evaluate various characteristics of core-shell nanostructures.

vii. Greener and sustainable synthetic methods can reduce environmental pollution to some extent, while attaining economic growth via green chemistry.

viii. Each method for core-shell nanostructure growth has some merits and demerits. Thus, it is difficult to recommend a particular method. The recent trends show that the one-step synthesis technique, due to its simplicity and low cost, is more viable for the commercial-scale production of the various core-shell nanostructures required for widespread application.

Author Contributions: Conceptualization, K.W.S. and H.W.K.; methodology, G.F.H.; software, K.W.S.; validation, K.W.S., H.W.K., and G.F.H.; formal analysis, G.F.H.; investigation, K.W.S.; resources, G.F.H.; data curation, K.W.S.; writing—original draft preparation, G.F.H.; writing—review and editing, K.W.S.; visualization, H.W.K.; supervision, K.W.S.; project administration, H.W.K.; and funding acquisition, H.W.K. All authors have read and agreed to the published version of the manuscript.

Funding: This work was supported by funding from the National University of Singapore. 
Institutional Review Board Statement: Not applicable.

Informed Consent Statement: Not applicable.

Conflicts of Interest: The authors declare no conflict of interest.

\section{References}

1. Lin, C.; Li, Y.; Yu, M.; Yang, P.; Lin, J. A facile synthesis and characterization of monodisperse spherical pigment particles with a core/shell structure. Adv. Funct. Mater. 2007, 17, 1459-1465. [CrossRef]

2. Torres-Cavanillas, R.; Lima-Moya, L.; Tichelaar, F.D.; Zandbergen, H.W.; Giménez-Marqués, M.; Coronado, E. Downsizing of robust Fe-triazole@SiO 2 spin-crossover nanoparticles with ultrathin shells. Dalton Trans. 2019, 48, 15465-15469. [CrossRef]

3. Alexander, M.; Mackechnie, J.; Yam, W. Carbonation of concrete bridge structures in three South African localities. Cem. Concr. Compos. 2007, 29, 750-759. [CrossRef]

4. Sadeghi-Niaraki, S.; Ghasemi, B.; Ghasemi, E.; Ghahari, M. Preparation of $(\mathrm{Fe}, \mathrm{Cr})_{2} \mathrm{O}_{3} @ \mathrm{TiO}_{2}$ cool pigments for energy saving applications. J. Alloys Compd. 2019, 779, 367-379. [CrossRef]

5. Soranakom, P.; Vittayakorn, N.; Rakkwamsuk, P.; Supothina, S.; Seeharaj, P. Effect of surfactant concentration on the formation of $\mathrm{Fe}_{2} \mathrm{O}_{3} @ \mathrm{SiO}_{2}$ NIR-reflective red pigments. Ceram. Int. 2021, 47, 13147-13155. [CrossRef]

6. Dong, X.; Zhang, X.; Yu, X.; Jiang, Z.; Liu, X.; Li, C.; Sun, Z.; Zheng, S.; Dionysiou, D.D. A novel rutile TiO $2 / \mathrm{AlPO}_{4}$ core-shell pigment with substantially suppressed photoactivity and enhanced dispersion stability. Powder Technol. 2020, 366, 537-545. [CrossRef]

7. Yao, B.; Geng, S.; Wang, J.; Wang, L. Synthesis, Characterization, and Optical Properties of Near-Infrared Reflecting Composite Inorganic Pigments Composed of $\mathrm{TiO}_{2} / \mathrm{CuO}$ Core-Shell Particles. Aust. J. Chem. 2018, 71, 373-379. [CrossRef]

8. Huseien, G.F.; Shah, K.W.; Sam, A.R.M. Sustainability of nanomaterials based self-healing concrete: An all-inclusive insight. J. Build. Eng. 2019, 23, 155-171. [CrossRef]

9. Izu, N.; Uchida, T.; Itoh, T.; Shin, W. Decreasing the shell ratio of core-shell type nanoparticles with a ceria core and polymer shell by acid treatment. Solid State Sci. 2018, 85, 32-37. [CrossRef]

10. Ahmed, N.; Fathi, A.; Mohamed, M.; Abd El-Gawad, W. Evaluation of new core-shell pigments on the anticorrosive performance of coated reinforced concrete steel. Prog. Org. Coat. 2020, 140, 105530. [CrossRef]

11. Sanchis-Gual, R.; Torres-Cavanillas, R.; Puchau, M.C.; Giménez-Marqués, M.; Coronado, E. Plasmon-assisted spin transition in gold nanostar@spin crossover heterostructures. J. Mater. Chem. C 2021. [CrossRef]

12. Torres-Cavanillas, R.; Sanchis-Gual, R.; Dugay, J.; Coronado-Puchau, M.; Giménez-Marqués, M.; Coronado, E. Design of Bistable Gold@Spin-Crossover Core-Shell Nanoparticles Showing Large Electrical Responses for the Spin Switching. Adv. Mater. 2019, 31, 1900039. [CrossRef]

13. Ahmed, N.M.; Mohamed, M.G.; Abd El-Gawad, W.M. Corrosion protection performance of silica fume waste-phosphates core-shell pigments. Pigment Resin Technol. 2018, 47, 261-271. [CrossRef]

14. Sertchook, H.; Avnir, D. Submicron silica/polystyrene composite particles prepared by a one-step sol-gel process. Chem. Mater. 2003, 15, 1690-1694. [CrossRef]

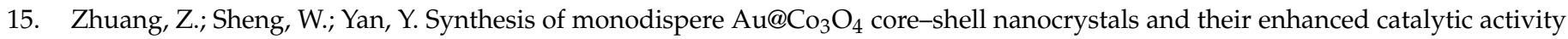
for oxygen evolution reaction. Adv. Mater. 2014, 26, 3950-3955. [CrossRef]

16. Zhong, Z.; Yin, Y.; Gates, B.; Xia, Y. Preparation of mesoscale hollow spheres of $\mathrm{TiO}_{2}$ and $\mathrm{SnO}_{2}$ by templating against crystalline arrays of polystyrene beads. Adv. Mater. 2000, 12, 206-209. [CrossRef]

17. Samal, A.K.; Polavarapu, L.; Rodal-Cedeira, S.; Liz-Marzán, L.M.; Pérez-Juste, J.; Pastoriza-Santos, I. Size Tunable Au@Ag coreshell nanoparticles: Synthesis and surface-enhanced raman scattering properties. Langmuir 2013, 29, 15076-15082. [CrossRef]

18. Parashar, M.; Shukla, V.K.; Singh, R. Metal oxides nanoparticles via sol-gel method: A review on synthesis, characterization and applications. J. Mater. Sci. Mater. Electron. 2020, 31, 3729-3749. [CrossRef]

19. Dugay, J.; Evers, W.; Torres-Cavanillas, R.; Giménez-Marqués, M.; Coronado, E.; Van der Zant, H.S. Charge Mobility and Dynamics in Spin-Crossover Nanoparticles Studied by Time-Resolved Microwave Conductivity. J. Phys. Chem. Lett. 2018, 9, 5672-5678. [CrossRef]

20. Ahmed, J.; Sharma, S.; Ramanujachary, K.V.; Lofland, S.E.; Ganguli, A.K. Microemulsion-mediated synthesis of cobalt (pure fcc and hexagonal phases) and cobalt-nickel alloy nanoparticles. J. Colloid Interface Sci. 2009, 336, 814-819. [CrossRef]

21. El-Safty, S.A. Synthesis, characterization and catalytic activity of highly ordered hexagonal and cubic composite monoliths. $J$. Colloid Interface Sci. 2008, 319, 477-488. [CrossRef]

22. Ghosh Chaudhuri, R.; Paria, S. Core/shell nanoparticles: Classes, properties, synthesis mechanisms, characterization, and applications. Chem. Rev. 2012, 112, 2373-2433. [CrossRef]

23. Han, W.; Yi, L.; Zhao, N.; Tang, A.; Gao, M.; Tang, Z. Synthesis and shape-tailoring of copper sulfide/indium sulfide-based nanocrystals. J. Am. Chem. Soc. 2008, 130, 13152-13161. [CrossRef]

24. Lee, H.; Kim, C.; Yang, S.; Han, J.W.; Kim, J. Shape-controlled nanocrystals for catalytic applications. Catal. Surv. Asia 2012, 16, 14-27. [CrossRef]

25. Libor, Z; Zhang, Q. The synthesis of nickel nanoparticles with controlled morphology and $\mathrm{SiO}_{2} / \mathrm{Ni}$ core-shell structures. Mater. Chem. Phys. 2009, 114, 902-907. [CrossRef] 
26. Kim, Y.; Pee, J.-H.; Chang, J.H.; Choi, K.; Kim, K.J.; Jung, D.-Y. Silica effect on coloration of hematite nanoparticles for red pigments. Chem. Lett. 2009, 38, 842-843. [CrossRef]

27. Liu, R.; Priestley, R.D. Rational design and fabrication of core-shell nanoparticles through a one-step/pot strategy. J. Mater. Chem. A 2016, 4, 6680-6692. [CrossRef]

28. Chen, S.; Cheng, M.; Lang, Y.; Tian, C.; Wei, H.; Wang, C.-A. Preparation and characterization of monodispersed spherical $\mathrm{Fe}_{2} \mathrm{O}_{3} @ \mathrm{SiO}_{2}$ reddish pigments with core-shell structure. J. Adv. Ceram. 2019, 8, 39-46. [CrossRef]

29. Dodd, A.C. A comparison of mechanochemical methods for the synthesis of nanoparticulate nickel oxide. Powder Technol. 2009, 196, 30-35. [CrossRef]

30. Deng, W.; Xia, W.; Li, C.; Tang, Y. Formation of ultra-fine grained materials by machining and the characteristics of the deformation fields. J. Mater. Process. Technol. 2009, 209, 4521-4526. [CrossRef]

31. Salari, M.; Marashi, P.; Rezaee, M. Synthesis of $\mathrm{TiO}_{2}$ nanoparticles via a novel mechanochemical method. J. Alloys Compd. 2009, 469, 386-390. [CrossRef]

32. Sasikumar, R.; Arunachalam, R. Synthesis of nanostructured aluminium matrix composite (AMC) through machining. Mater. Lett. 2009, 63, 2426-2428. [CrossRef]

33. Wang, Y.; Cai, K.; Yao, X. Facile synthesis of PbTe nanoparticles and thin films in alkaline aqueous solution at room temperature. J. Solid State Chem. 2009, 182, 3383-3386. [CrossRef]

34. Yoo, S.-H.; Liu, L.; Park, S. Nanoparticle films as a conducting layer for anodic aluminum oxide template-assisted nanorod synthesis. J. Colloid Interface Sci. 2009, 339, 183-186. [CrossRef] [PubMed]

35. Oldenburg, S.; Averitt, R.; Westcott, S.; Halas, N. Nanoengineering of optical resonances. Chem. Phys. Lett. 1998, $288,243-247$. [CrossRef]

36. Daniel, M.-C.; Astruc, D. Gold nanoparticles: Assembly, supramolecular chemistry, quantum-size-related properties, and applications toward biology, catalysis, and nanotechnology. Chem. Rev. 2004, 104, 293-346. [CrossRef] [PubMed]

37. Pal, G.; Rai, P.; Pandey, A. Green synthesis of nanoparticles: A greener approach for a cleaner future. In Green Synthesis, Characterization and Applications of Nanoparticles; Elsevier: Amsterdam, The Netherlands, 2019; Volume 1, pp. 1-26.

38. Galogahi, F.M.; Zhu, Y.; An, H.; Nguyen, N.-T. Core-shell microparticles: Generation approaches and applications. J. Sci. Adv. Mater. Devices 2020, 5, 417-435. [CrossRef]

39. Cao, L.; Fei, X.; Zhao, H.; Gu, Y. Inorganic-organic hybrid pigment fabricated in the preparation process of organic pigment: Preparation and characterization. Dye Pigments 2015, 119, 75-83. [CrossRef]

40. Bongur, R.; Le Nouen, D.; Gaslain, F.; Marichal, C.; Lebeau, B.; Guarilloff, P. Red 33 dye co-encapsulated with cetyltrimethylammonium in mesoporous silica materials. Dye Pigments 2016, 127, 1-8. [CrossRef]

41. Fei, X.; Zhang, T.; Zhou, C. Modification study involving a Naphthol as red pigment. Dye Pigments 2000, 44, 75-80.

42. Chen, G.; Zhu, Z.; Liu, H.; Wu, Y.; Zhu, C. Preparation of $\mathrm{SiO}_{2}$ coated $\mathrm{Ce}_{2} \mathrm{~S}_{3}$ red pigment with improved thermal stability. J. Rare Earths 2013, 31, 891-896. [CrossRef]

43. Yu, S.; Wang, D.; Liu, Y.; Li, Z.; Zhang, X.; Yang, X.; Wang, Y.; Wang, X.; Su, H. Preparations and characterizations of $\gamma-\mathrm{Ce}_{2} \mathrm{~S}_{3} @ S i \mathrm{O}_{2}$ pigments from precoated $\mathrm{CeO}_{2}$ with improved thermal and acid stabilities. RSC Adv. 2014, 4, 23653-23657. [CrossRef]

44. Guo, Q.; Zhou, Y.; Nie, W.; Chen, P.; Song, L. Synthesis of highly monodispersed $\mathrm{CdS} / \mathrm{SiO}_{2}$ core shell nanoparticles and their photocatalytic activities. J. Nanosci. Nanotechnol. 2015, 15, 2364-2370. [CrossRef]

45. Zhang, Y.; Fan, L.; Chen, H.; Zhang, J.; Zhang, Y.; Wang, A. Learning from ancient Maya: Preparation of stable palygorskite/methylene blue@SiO ${ }_{2}$ Maya Blue-like pigment. Microporous Mesoporous Mater. 2015, 211, 124-133. [CrossRef]

46. Zhang, Y.; Zhang, J.; Wang, A. Facile preparation of stable palygorskite/methyl violet@SiO 2 "Maya Violet" pigment. J. Colloid Interface Sci. 2015, 457, 254-263. [CrossRef] [PubMed]

47. Fabjan, E.Š.; Škapin, A.S.; Škrlep, L.; Živec, P.; Čeh, M.; Gaberšček, M. Protection of organic pigments against photocatalysis by encapsulation. J. Sol-Gel Sci. Technol. 2012, 62, 65-74. [CrossRef]

48. Fabjan, E.Š.; Otoničar, M.; Gaberšček, M.; Škapin, A.S. Surface protection of an organic pigment based on a modification using a mixed-micelle system. Dye Pigments 2016, 127, 100-109. [CrossRef]

49. Fei, X.; Cao, L.; Liu, Y. Modified CI Pigment Red 170 with a core-shell structure: Preparation, characterization and computational study. Dye Pigments 2016, 125, 192-200. [CrossRef]

50. Yuan, J.; Zhou, S.; Gu, G.; Wu, L. Encapsulation of organic pigment particles with silica via sol-gel process. J. Sol-Gel Sci. Technol. 2005, 36, 265-274. [CrossRef]

51. Horiuchi, S.; Horie, S.; Ichimura, K. Core-Shell Structures of Silica-Organic Pigment Nanohybrids Visualized by Electron Spectroscopic Imaging. ACS Appl. Mater. Interfaces 2009, 1, 977-981. [CrossRef]

52. Yuan, J.; Xing, W.; Gu, G.; Wu, L. The properties of organic pigment encapsulated with nano-silica via layer-by-layer assembly technique. Dye Pigments 2008, 76, 463-469. [CrossRef]

53. Lu, Y.; Yin, Y.; Mayers, B.T.; Xia, Y. Modifying the surface properties of superparamagnetic iron oxide nanoparticles through a sol-gel approach. Nano Lett. 2002, 2, 183-186. [CrossRef]

54. Tago, T.; Tashiro, S.; Hashimoto, Y.; Wakabayashi, K.; Kishida, M. Synthesis and optical properties of $\mathrm{SiO}_{2}-\mathrm{coated}_{\mathrm{CeO}}$ nanoparticles. J. Nanopart. Res. 2003, 5, 55-60. [CrossRef]

55. Wang, A.; Ge, C.; Yin, H.; Ren, M.; Zhang, Y.; Zhou, Q.; Wu, Z.; Huo, J.; Li, X.; Jiang, T. Evolution of binary $\mathrm{Fe}_{2} \mathrm{O}_{3} / \mathrm{SiO}_{2}$ coating layers on the surfaces of aluminum flakes and the pigmentary performances. Powder Technol. 2012, 221, 306-311. [CrossRef] 
56. Ahmed, N.M.; Abd El-Gawad, W.M.; Souaya, E.M. Evaluation of the anticorrosive performance of epoxy coatings containing new core/shell pigments. Pigment Resin Technol. 2018, 7, 116-126. [CrossRef]

57. Li, Y.; Le, S.; Wang, Z.; Hong, Y.; Li, K.; Pu, Q. Preparation and characterization of the $\mathrm{Sr}_{2}+-$ doped $\gamma-\mathrm{Ce}_{2} \mathrm{~S}_{3} @ \mathrm{c}-\mathrm{SiO}_{2}$ red pigments exhibiting improved temperature and acid stability. Appl. Surf. Sci. 2020, 508, 145266. [CrossRef]

58. Mjejri, I.; Mornet, S.; Gaudon, M. From nano-structured polycrystalline spheres with $\mathrm{Zn}_{1-\mathrm{x}} \mathrm{Co}_{\mathrm{x}} \mathrm{O}$ composition to core-shell $\mathrm{Zn}_{1^{-} \mathrm{x}} \mathrm{Co}_{\mathrm{x}} \mathrm{O} @ \mathrm{SiO}_{2}$ as green pigments. J. Alloys Compd. 2019, 777, 1204-1210. [CrossRef]

59. Fabjan, E.Š.; Saghi, Z.; Midgley, P.A.; Otoničar, M.; Dražić, G.; Gaberšček, M.; Škapin, A.S. Diketopyrrolopyrrole pigment core@multi-layer $\mathrm{SiO}_{2}$ shell with improved photochemical stability. Dye Pigments 2018, 156, 108-115. [CrossRef]

60. Yu, R.; An, G.S.; Pee, J.-H.; Kim, Y. Evaluation of Color and Structure of $\alpha-\mathrm{Fe}_{2} \mathrm{O}_{3}$ Nanocapsules by Tuning of the SiO $\mathrm{Morphology}$ J. Nanosci. Nanotechnol. 2018, 18, 6133-6136. [CrossRef] [PubMed]

61. Wang, F.; Zhang, X.; Lin, Y.; Wang, L.; Zhu, J. Structural coloration pigments based on carbon modified $\mathrm{ZnS@SiO}_{2}$ nanospheres with low-angle dependence, high color saturation, and enhanced stability. ACS Appl. Mater. Interfaces 2016, 8, 5009-5016. [CrossRef] [PubMed]

62. Liu, S.-G.; Li, Y.-M.; Wang, Z.-M.; Shen, Z.-Y.; Xie, Z.-X. Enhanced high temperature oxidization resistance of silica coated $\gamma$-Ce $\mathrm{S}_{3}$ red pigments. Appl. Surf. Sci. 2016, 387, 1147-1153. [CrossRef]

63. Sultan, S.; Kareem, K.; He, L. Synthesis, characterization and resistant performance of $\alpha-\mathrm{Fe}_{2} \mathrm{O}_{3} @ \mathrm{SiO}_{2}$ composite as pigment protective coatings. Surf. Coat. Technol. 2016, 300, 42-49. [CrossRef]

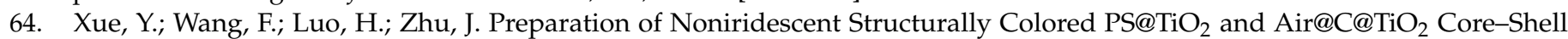
Nanoparticles with Enhanced Color Stability. ACS Appl. Mater. Interfaces 2019, 11, 34355-34363. [CrossRef] [PubMed]

65. Sadeghi-Niaraki, S.; Ghasemi, B.; Habibolahzadeh, A.; Ghasemi, E.; Ghahari, M. Nanostructured $\mathrm{Fe}_{2} \mathrm{O}_{3} @ \mathrm{TiO}_{2}$ pigments with improved NIR reflectance and photocatalytic ability. Mater. Chem. Phys. 2019, 235, 121769. [CrossRef]

66. Sun, D.; Cao, Y.; Xu, Y.; Zhang, G.; Sun, Y. Tunable synthesis of core-shell $\alpha-\mathrm{Fe}_{2} \mathrm{O}_{3} / \mathrm{TiO}_{2}$ composite nanoparticles and their visible-light photocatalytic activity. Chem. Res. Chin. Univ. 2016, 32, 882-888. [CrossRef]

67. Yang, S.; Xu, Y.; Sun, Y.; Zhang, G.; Gao, D. Size-controlled synthesis, magnetic property, and photocatalytic property of uniform $\alpha-\mathrm{Fe}_{2} \mathrm{O}_{3}$ nanoparticles via a facile additive-free hydrothermal route. Cryst. Eng. Commun. 2012, 14, 7915-7921. [CrossRef]

68. Zhang, X.; Xie, Y.; Chen, H.; Guo, J.; Meng, A.; Li, C. One-dimensional mesoporous $\mathrm{Fe}_{2} \mathrm{O}_{3} @ \mathrm{TiO}_{2}$ core-shell nanocomposites: Rational design, synthesis and application as high-performance photocatalyst in visible and UV light region. Appl. Surf. Sci. 2014, 317, 43-48. [CrossRef]

69. He, X.; Wang, F.; Liu, H.; Li, J.; Niu, L. Synthesis and coloration of highly dispersed $\mathrm{NiTiO}_{3} @ \mathrm{TiO}_{2}$ yellow pigments with core-shell structure. J. Eur. Ceram. Soc. 2017, 37, 2965-2972. [CrossRef]

70. He, X.; Wang, F.; Liu, H.; Li, J.; Niu, L. Fabrication of highly dispersed $\mathrm{NiTiO}_{3} @ \mathrm{TiO}_{2}$ yellow pigments with enhanced NIR reflectance. Mater. Lett. 2017, 208, 82-85. [CrossRef]

71. Montes-Hernandez, G.; Pironon, J.; Villieras, F. Synthesis of a red iron oxide/montmorillonite pigment in a $\mathrm{CO}_{2}$-rich brine solution. J. Colloid Interface Sci. 2006, 303, 472-476. [CrossRef]

72. Legodi, M.A.; de Waal, D. The preparation of magnetite, goethite, hematite and maghemite of pigment quality from mill scale iron waste. Dye Pigments 2007, 74, 161-168. [CrossRef]

73. Kumari, L.S.; Rao, P.P.; Reddy, M.L. Environment-friendly red pigments from $\mathrm{CeO}_{2}-\mathrm{Fe}_{2} \mathrm{O}_{3}-\mathrm{Pr}_{6} \mathrm{O}_{11}$ solid solutions. J. Alloys Compd. 2008, 461, 509-515. [CrossRef]

74. Hosseini-Zori, M.; Bondioli, F.; Manfredini, T.; Taheri-Nassaj, E. Effect of synthesis parameters on a hematite-silica red pigment obtained using a coprecipitation route. Dye Pigments 2008, 77, 53-58. [CrossRef]

75. Llusar, M.; Royo, V.; Badenes, J.; Tena, M.; Monrós, G. Nanocomposite $\mathrm{Fe}_{2} \mathrm{O}_{3}-\mathrm{SiO}_{2}$ inclusion pigments from post-functionalized mesoporous silicas. J. Eur. Ceram. Soc. 2009, 29, 3319-3332. [CrossRef]

76. Hong, R.-Y.; Li, J.-H.; Zhang, S.-Z.; Li, H.-Z.; Zheng, Y.; Ding, J.-m.; Wei, D.-G. Preparation and characterization of silica-coated $\mathrm{Fe}_{3} \mathrm{O}_{4}$ nanoparticles used as precursor of ferrofluids. Appl. Surf. Sci. 2009, 255, 3485-3492. [CrossRef]

77. Yu, R.; Kim, Y.; Pee, J.-H.; Kim, K.J.; Kim, W. Thermal behavior and coloration study of silica-coated $\alpha-\mathrm{Fe}_{2} \mathrm{O}_{3}$ and $\beta$-FeOOH nanocapsules. J. Nanosci. Nanotechnol. 2011, 11, 6283-6286. [CrossRef]

78. Rahimi, R.; Heidari-Golafzani, M.; Rabbani, M. Preparation and photocatalytic application of $\mathrm{ZnFe}_{2} \mathrm{O}_{4} @ \mathrm{ZnO}$ core-shell nanostructures. Superlattices Microstruct. 2015, 85, 497-503. [CrossRef]

79. Zhang, X.-S.; Wang, J.-X.; Xu, K.; Le, Y.; Chen, J.-F. Monodisperse Ag@SiO 2 Core-Shell Nanoparticles as Active Inhibitors for Marine Anticorrosion Applications. J. Nanosci. Nanotechnol. 2011, 11, 3481-3487. [CrossRef]

80. Fang, Q.; Liang, X. $\mathrm{CeO}_{2}-\mathrm{Al}_{2} \mathrm{O}_{3}, \mathrm{CeO}_{2}-\mathrm{SiO}_{2}, \mathrm{CeO}_{2}-\mathrm{TiO}_{2}$ core-shell spheres: Formation mechanisms and UV absorption. RSC Adv. 2012, 2, 5370-5375. [CrossRef]

81. Liang, X.; Xiao, J.; Chen, B.; Li, Y. Catalytically stable and active $\mathrm{CeO}_{2}$ mesoporous spheres. Inorg. Chem. 2010, 49, 8188-8190. [CrossRef] [PubMed]

82. Chopin, T.; Guichon, H.; Touret, O. Rare Earth Sesquisulfide Compositions Comprising Alkali/Alkaline Earth Metal Values. U.S. Patent No. 5,348,581, 20 September 1994.

83. Duan, J.; Feng, Y.; Wang, W.; Li, X. Novel modification method of yellow pigment and its potential application in e-ink. Mater. Res. Innov. 2010, 14, 113-118. [CrossRef] 
84. Zou, J.; Zheng, W. $\mathrm{TiO}_{2} @ \mathrm{CoTiO}_{3}$ complex green pigments with low cobalt content and tunable color properties. Ceram. Int. 2016, 42, 8198-8205. [CrossRef]

85. Hayes, R.; Ahmed, A.; Edge, T.; Zhang, H. Core-shell particles: Preparation, fundamentals and applications in high performance liquid chromatography. J. Chromatogr. A 2014, 1357, 36-52. [CrossRef]

86. Mao, W.-X.; Zhang, W.; Chi, Z.-X.; Lu, R.-W.; Cao, A.-M.; Wan, L.-J. Core-shell structured Ce $\mathrm{S}_{3} @ Z n O$ and its potential as a pigment. J. Mater. Chem. A 2015, 3, 2176-2180. [CrossRef]

87. Liu, J.; Qiao, S.Z.; Chen, J.S.; Lou, X.W.D.; Xing, X.; Lu, G.Q.M. Yolk/shell nanoparticles: New platforms for nanoreactors, drug delivery and lithium-ion batteries. Chem. Commun. 2011, 47, 12578-12591. [CrossRef]

88. Niu, H.-Y.; Li, W.-H.; Shi, Y.-L.; Cai, Y.-Q. A core-shell magnetic mesoporous silica sorbent for organic targets with high extraction performance and anti-interference ability. Chem. Commun. 2011, 47, 4454-4456.

89. Insin, N.; Tracy, J.B.; Lee, H.; Zimmer, J.P.; Westervelt, R.M.; Bawendi, M.G. Incorporation of iron oxide nanoparticles and quantum dots into silica microspheres. ACS Nano 2008, 2, 197-202. [CrossRef] [PubMed]

90. Wang, J.; Yang, N.; Tang, H.; Dong, Z.; Jin, Q.; Yang, M.; Kisailus, D.; Zhao, H.; Tang, Z.; Wang, D. Accurate control of multishelled $\mathrm{Co} 3 \mathrm{O} 4$ hollow microspheres as high-performance anode materials in lithiumion batteries. Angew. Chem. 2013, 125, 6545-6548. [CrossRef]

91. Lai, X.; Li, J.; Korgel, B.A.; Dong, Z.; Li, Z.; Su, F.; Du, J.; Wang, D. General synthesis and gas-sensing properties of multiple-shell metal oxide hollow microspheres. Angew. Chem. Int. Ed. 2011, 50, 2738-2741. [CrossRef] [PubMed]

92. Wang, D.; Xin, H.L.; Hovden, R.; Wang, H.; Yu, Y.; Muller, D.A.; DiSalvo, F.J.; Abruña, H.D. Structurally ordered intermetallic platinum-cobalt core-shell nanoparticles with enhanced activity and stability as oxygen reduction electrocatalysts. Nat. Mater. 2013, 12, 81-87. [CrossRef]

93. Chae, H.S.; Kim, S.D.; Piao, S.H.; Choi, H.J. Core-shell structured $\mathrm{Fe}_{3} \mathrm{O}_{4} @ \mathrm{SiO}_{2}$ nanoparticles fabricated by sol-gel method and their magnetorheology. Colloid Polym. Sci. 2016, 294, 647-655. [CrossRef]

94. Guo, X.; Canet, J.-L.; Boyer, D.; Gautier, A.; Mahiou, R. Sol-gel emulsion synthesis of biphotonic core-shell nanoparticles based on lanthanide doped organic-inorganic hybrid materials. J. Mater. Chem. 2012, 22, 6117-6122. [CrossRef]

95. Li, Y.-M.; Liu, S.-G.; Song, F.-S.; Wang, Z.-M.; Shen, Z.-Y.; Xie, Z.-X. Preparation and thermal stability of silica layer multicoated $\gamma$-Ce2S3 red pigment microparticles. Surf. Coat. Technol. 2018, 345, 70-75. [CrossRef]

96. Nikolaev, P.; Bronikowski, M.J.; Bradley, R.K.; Rohmund, F.; Colbert, D.T.; Smith, K.; Smalley, R.E. Gas-phase catalytic growth of single-walled carbon nanotubes from carbon monoxide. Chem. Phys. Lett. 1999, 313, 91-97. [CrossRef]

97. El-Gendy, A.; Ibrahim, E.; Khavrus, V.; Krupskaya, Y.; Hampel, S.; Leonhardt, A.; Büchner, B.; Klingeler, R. The synthesis of carbon coated $\mathrm{Fe}, \mathrm{Co}$ and Ni nanoparticles and an examination of their magnetic properties. Carbon 2009, 47, 2821-2828. [CrossRef]

98. Mendes, R.G.; Koch, B.; Bachmatiuk, A.; El-Gendy, A.A.; Krupskaya, Y.; Springer, A.; Klingeler, R.; Schmidt, O.; Büchner, B.; Sanchez, S. Synthesis and toxicity characterization of carbon coated iron oxide nanoparticles with highly defined size distributions. Biochim. Biophys. Acta BBA Gen. Subj. 2014, 1840, 160-169. [CrossRef]

99. Stöber, W.; Fink, A.; Bohn, E. Controlled growth of monodisperse silica spheres in the micron size range. J. Colloid Interface Sci. 1968, 26, 62-69. [CrossRef]

100. Bogush, G.; Tracy, M.; Zukoski Iv, C. Preparation of monodisperse silica particles: Control of size and mass fraction. J. Non-Cryst. Solids 1988, 104, 95-106. [CrossRef]

101. Drašar, P. The Sol-Gel Handbook: Synthesis, Characterization and Applications; David, L., Marcos, Z., Eds.; Wiley: Hoboken, NJ, USA, 2016.

102. Du, G.-H.; Liu, Z.; Xia, X.; Chu, Q.; Zhang, S. Characterization and application of $\mathrm{Fe}_{3} \mathrm{O}_{4} / \mathrm{SiO}_{2}$ nanocomposites. J. Sol. Gel. Sci. Technol. 2006, 39, 285-291. [CrossRef]

103. Li, Z.; Wanjala, B.; Cernigliaro, G.; Nawrocki, D.; Gu, Z. Synthesis of $\mathrm{Zn}_{2} \mathrm{SiO}_{4} @ Z n O$ core-shell nanoparticles and the effect of shell thickness on band-gap transition. Mater. Chem. Phys. 2020, 240, 122144. [CrossRef]

104. Tsuji, M.; Yamaguchi, D.; Matsunaga, M.; Ikedo, K. Epitaxial growth of Au@Ni core- shell nanocrystals prepared using a two-step reduction method. Cryst. Growth Des. 2011, 11, 1995-2005. [CrossRef]

105. Fan, F.-R.; Liu, D.-Y.; Wu, Y.-F.; Duan, S.; Xie, Z.-X.; Jiang, Z.-Y.; Tian, Z.-Q. Epitaxial growth of heterogeneous metal nanocrystals: From gold nano-octahedra to palladium and silver nanocubes. J. Am. Chem. Soc. 2008, 130, 6949-6951. [CrossRef] [PubMed]

106. Wu, Y.; Jiang, P.; Jiang, M.; Wang, T.-W.; Guo, C.-F.; Xie, S.-S.; Wang, Z.-L. The shape evolution of gold seeds and gold@silver core-shell nanostructures. Nanotechnology 2009, 20, 305602. [CrossRef]

107. Tsuji, M.; Yamaguchi, D.; Matsunaga, M.; Alam, M.J. Epitaxial Growth of Au@Cu Core- Shell Nanocrystals Prepared Using the PVP-Assisted Polyol Reduction Method. Cryst. Growth Des. 2010, 10, 5129-5135. [CrossRef]

108. Habas, S.E.; Lee, H.; Radmilovic, V.; Somorjai, G.A.; Yang, P. Shaping binary metal nanocrystals through epitaxial seeded growth. Nat. Mater. 2007, 6, 692-697. [CrossRef]

109. Tsuji, M.; Hikino, S.; Tanabe, R.; Yamaguchi, D. Synthesis of Ag@Cu Core-Shell Nanoparticles in High Yield Using a Polyol Method. Chem. Lett. 2010, 39, 334-336. [CrossRef]

110. Sharma, R.; Tiwari, S. Synthesis of fly ash based core-shell composites for use as functional pigment in paints. In Proceedings of the AIP Conference Proceedings 2016, Jaipur, Rajasthan, India, 24-25 October 2015; pp. 020083-1-020083-6.

111. Zhang, J.; Li, X.; Shi, X.; Hua, M.; Zhou, X.; Wang, X. Synthesis of core-shell acrylic-polyurethane hybrid latex as binder of aqueous pigment inks for digital inkjet printing. Prog. Nat. Sci. Mater. Int. 2012, 22, 71-78. [CrossRef] 
112. Guan, L.; Fan, J.; Zhang, Y.; Guo, Y.; Duan, H.; Chen, Y.; Li, H.; Liu, H. Facile preparation of highly cost-effective BaSO @BiVO $4_{4}$ core-shell structured brilliant yellow pigment. Dye Pigments 2016, 128, 49-53. [CrossRef]

113. Li, Y.; Gao, Y.; Wang, Z.; Shen, Z.; Hong, Y.; Song, F. Synthesis and characterization of aluminum-based $\gamma$-Ce $\mathrm{S}_{2} \mathrm{~S}_{3}$ composite red pigments by microemulsion method. J. Alloys Compd. 2020, 812, 152100. [CrossRef]

114. Ahmed, N.M.; Abdel-Fatah, H.T.M.; Youssef, E.A. Corrosion studies on tailored Zn·Co aluminate/kaolin core-shell pigments in alkyd based paints. Prog. Org. Coat. 2012, 73, 76-87. [CrossRef]

115. Jang, H.-S.; Kang, H.-S.; So, S.-Y. Color expression characteristics and physical properties of colored mortar using ground granulated blast furnace slag and White Portland Cement. KSCE J. Civ. Eng. 2014, 18, 1125-1132. [CrossRef]

116. Lee, H.J.; Jung, K.Y.; Kim, Y.S. Nanostructured $\mathrm{Fe}_{2} \mathrm{O}_{3} / \mathrm{TiO}_{2}$ composite particles with enhanced NIR reflectance for application to LiDAR detectable cool pigments. RSC Adv. 2021, 11, 16834-16840. [CrossRef] 